\title{
Sexual Conflict and Seminal Fluid Proteins: A Dynamic Landscape of Sexual Interactions
}

\author{
Laura K. Sirot ${ }^{1}$, Alex Wong ${ }^{2}$, Tracey Chapman ${ }^{3}$, and Mariana F. Wolfner ${ }^{4}$ \\ ${ }^{1}$ Department of Biology, College of Wooster, Wooster, Ohio 44691 \\ ${ }^{2}$ Department of Biology, Carleton University, Ottawa, Ontario K1S 5B6, Canada \\ ${ }^{3}$ School of Biological Sciences, University of East Anglia, Norwich Research Park, Norwich NR4 7TJ, \\ United Kingdom \\ ${ }^{4}$ Department of Molecular Biology and Genetics, Cornell University, Ithaca, New York 14853 \\ Correspondence: mfw5@cornell.edu; tracey.chapman@uea.ac.uk
}

Sexual reproduction requires coordinated contributions from both sexes to proceed efficiently. However, the reproductive strategies that the sexes adopt often have the potential to give rise to sexual conflict because they can result in divergent, sex-specific costs and benefits. These conflicts can occur at many levels, from molecular to behavioral. Here, we consider sexual conflict mediated through the actions of seminal fluid proteins. These proteins provide many excellent examples in which to trace the operation of sexual conflict from molecules through to behavior. Seminal fluid proteins are made by males and provided to females during mating. As agents that can modulate egg production at several steps, as well as reproductive behavior, sperm "management," and female feeding, activity, and longevity, the actions of seminal proteins are prime targets for sexual conflict. We review these actions in the context of sexual conflict. We discuss genomic signatures in seminal protein (and related) genes that are consistent with current or previous sexual conflict. Finally, we note promising areas for future study and highlight real-world practical situations that will benefit from understanding the nature of sexual conflicts mediated by seminal proteins.

$\mathrm{B}$ th sexes benefit from successful reproduction, but the different reproductive strategies adopted by males and females may result in differential costs and benefits. This can result in sexual conflict before, during, and after mating. Conflict in the more familiar form of competition can also occur between females and between males, with the latter situation including interejaculate competition. Of the many "weapons" in these conflicts and competitions, this article focuses on the seminal fluid proteins

(SFPs) that are made by males and transferred to females during mating. These proteins represent a crucial interface of functional activity between male and female. Transfer of SFPs can affect physiology and, in some animals, the behavior and life span of mated females (reviewed in Chapman 2001; Gillott 2003; Poiani 2006; Avila et al. 2011; Rodríguez-Martínez et al. 2011). Because SFPs have important effects on the most intimate of interactions between the sexes, they are prime candidates to become subject to sex-

Editors: William R. Rice and Sergey Gavrilets

Additional Perspectives on The Genetics and Biology of Sexual Conflict available at www.cshperspectives.org

Copyright (C) 2015 Cold Spring Harbor Laboratory Press; all rights reserved; doi: 101101/cshperspect.a017533 Cite this article as Cold Spring Harb Perspect Biol 2015;7:a017533 
L.K. Sirot et al.

ually antagonistic selection (Arnqvist and Rowe 2005). With increasing knowledge of the functions of SFPs, their roles in inter- and intrasexual conflict and their evolutionary responses to conflict are becoming ever more apparent. Here, we explore the roles, evolution, and significance of these male-derived players in sexual conflict. We refer the reader to previous reviews for much of the detailed functional information on SFPs (e.g., Chapman 2001; Gillott 2003; Kubli 2003; Arnqvist and Rowe 2005; Poiani 2006; Sirot et al. 2009; Avila et al. 2011; Rodríguez-Martínez et al. 2011) and focus here instead on selected examples, drawn largely from the study of insects.

\section{THE BATTLEGROUND}

The opportunity for postmating conflict is played out through the behavior and physiology of the mated female and the fate of sperm in the female reproductive tract. After mating has begun, male-derived molecules and sperm interact with female-derived molecules, cells, and tissues both within the female reproductive tract (e.g., Yapici et al. 2008; Hasemeyer et al. 2009; Yang et al. 2009; Dean 2013; Rubinstein and Wolfner 2013; Bromfield et al. 2014) and, in the case of some male-derived molecules, elsewhere in the female (e.g., Lung and Wolfner 1999). These interactions result in changes in female gene expression, behavior, physiology, life span, and morphology (reviewed in Gillott 2003; Poiani 2006; Robertson 2007; Avila et al. 2011). These changes, in turn, affect both male and female reproductive success. As a result, the battleground between males and females over postmating responses occurs in several parts of the female body including the reproductive tract and the nervous system.

\section{The Potential Weapons}

The proteins that accompany sperm into the female-once dismissed as simply a supportive medium for sperm - are now known to be potent modulators of female reproductive biology; in some cases, they even have effects on offspring (reviewed in Martan and Shepherd 1976; Chapman 2001; Gillott 2003; Kubli 2003; Poiani
2006; Sirot et al. 2009; Avila et al. 2011; Rodríguez-Martínez et al. 2011; Ratto et al. 2012; Bromfield et al. 2014). Most SFPs are the products of secretory glands in the male reproductive tract; these include the prostate glands, epididymi, and seminal vesicles of mammals (Poiani 2006; Rodríguez-Martínez et al. 2011) and the male accessory glands and ejaculatory ducts / bulb of arthropods (Gillott 2003). These tissues produce, modify, and store secreted proteins that are then transferred to females during mating, along with sperm. For some species there are comprehensive data on SFPs from large-scale transcriptomic and/or proteomic analyses (e.g., Collins et al. 2006; Pilch and Mann 2006; Dottorini et al. 2007; Findlay et al. 2008, 2009; Sirot et al. 2008, 2011; Walters and Harrsion 2008, 2010; Baer et al. 2009; Dean et al. 2009; Ramm et al. 2009; Rogers et al. 2009; Claw 2013). In others, only a partial complement of SFPs has been identified so far (e.g., Andrés et al. 2006, 2008; Davies and Chapman 2006; South et al. 2011; Simmons et al. 2013).

In organisms in which SFPs have been globally characterized, an amazing complexity is apparent. First, they are numerous; latest estimates are just more than 200 different SFPs in Drosophila melanogaster (Swanson et al. 2001; Ravi Ram and Wolfner 2007; Findlay et al. 2008; Avila et al. 2009); several hundred in mice (Dean et al. 2009) and humans (Pilch and Mann 2006); and between 50 and 100 in honeybees (Baer et al. 2009) and in mosquitoes (Rogers et al. 2009; Sirot et al. 2011). Yet, even these SFP inventories are likely incomplete. Second, the molecular characteristics of SFPs are fascinating. On the one hand, many of the biochemical classes of molecules in seminal fluids are similar across all animals (Mueller et al. 2004; Baer et al. 2009). For example, seminal fluids contain many proteases and protease inhibitors, sugarbinding lectins, cysteine-rich secretory proteins (CRISPs), antimicrobial and antioxidant proteins, and coagulation proteins such as transglutaminases, small peptides, and larger, prohormone-like, molecules (Avila et al. 2011). On the other hand, although these conserved types of proteins are observed in the seminal fluid of all animals examined to date, an unusu- 
ally high fraction of SFPs show rapid sequence evolution (e.g., Swanson and Vacquier 2002; Clark and Swanson 2005; Mueller et al. 2005; Clark et al. 2006; Haerty et al. 2007; Walters et al. 2010). SFPs of the same classes in different species are often not orthologous. For example, although the seminal fluid of two mosquito species and of D. melanogaster contains trypsinclass proteases that are predicted to have biochemically similar activities, those proteins are not orthologs (Findlay et al. 2008; Mancini et al. 2011; Sirot et al. 2011). Moreover, there is much redundancy in the types of protein present in the seminal fluid. For example, there are more than 15 trypsin-class proteases in $D$. melanogaster seminal fluid, and multiple serine proteases in mammalian seminal fluid (see LaFlamme and Wolfner 2012 for review). Although each SFP may have particular target proteins, it seems likely that different SFPs can also compensate for one another. These latter features (rapid evolution and nonorthology, as well as the frequent presence of redundancy) require explanation. One possibility is that this evolutionary exuberance is caused by coevolutionary arms races between SFPs in males and their receptors in females driven by sexual conflict. The evidence for this hypothesis is discussed in a section further below (see Does Sexual Conflict Shape SFP Evolution?).

Another likely contributor to complexity is that multiple seminal proteins could be needed to accomplish a single functional goal. For example, a network of at least eight Drosophila SFPs is required to bind a ninth SFP (the sex peptide, SP) to sperm. This binding to sperm prolongs the phenotypic effect of SP in females (Peng et al. 2005; Ravi Ram et al. 2009; Findlay et al. 2014). In another example from Drosophila, at least two SFPs (ovulin and Acp36DE) are proteolytically processed once inside the female (Fig. 1), and ectopic expression studies of

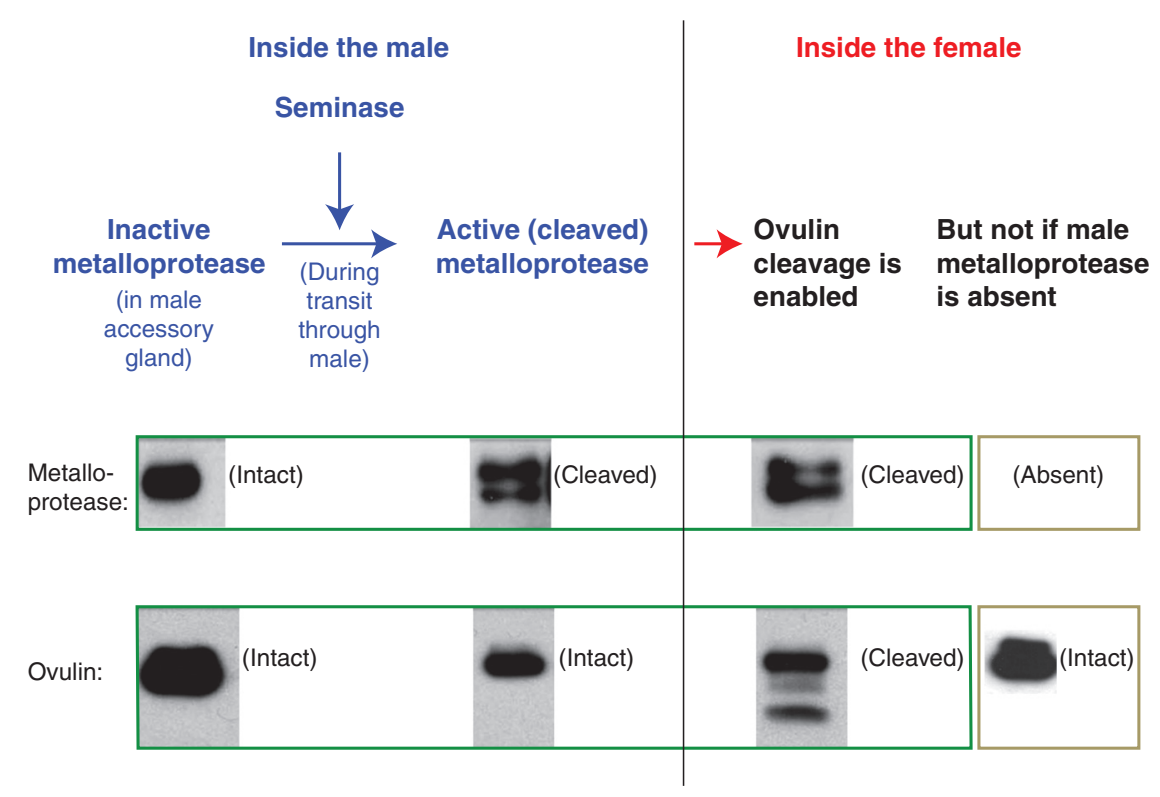

Figure 1. The molecular cascade that governs the cleavage of the seminal protein ovulin. Biochemical studies show that ovulin cleavage requires activation of a male metalloprotease during transit through the male during mating (Park and Wolfner 1995; Ravi Ram et al. 2006; LaFlamme et al. 2012, 2014). Ovulin and the two proteases that are needed to cleave it (seminase and the metalloprotease CG11864) are all made in the male's accessory gland but are stored uncleaved in this tissue. During transit through the male, the metalloprotease is activated by cleavage that is initiated by the serine protease "seminase." Although this metalloprotease is essential for ovulin cleavage within mated females, even after being activated, it does not cleave ovulin until all the proteins have entered females. (Western blot panels from Ravi Ram et al. 2006; reprinted, with permission, from the authors.) 
L.K. Sirot et al.

ovulin suggest that the processing generates a more active portion of ovulin (Heifetz et al. 2005). The proteolytic processing only occurs once the proteins are within the female, and is mediated by at least two seminal proteases. These proteases are made in the same tissue as their targets (i.e., the male accessory glands) and are kept inactive during storage. They are activated through sequential proteolysis as they and their targets move through the male and into and through the female reproductive tract (Park and Wolfner 1995; Heifetz et al. 2005; Ravi Ram et al. 2006; LaFlamme et al. 2012, 2014). A proteolytic cascade involving multiple seminal proteins is also observed in mammals: Liquefaction of the seminal clot, a process that is thought to facilitate sperm movement, is regulated by a cascade of multiple seminal proteases and protease inhibitors (Pampalakis and Sotiropoulau 2007). Evolutionary pressures derived from sexual conflict could affect various members of the multiple proteins that regulate a specific effect on females, so interpreting data on the evolutionary dynamics of any one molecule is complex.

A further reason for complexity of SFPs is that different members of a given biochemical family could potentially be co-opted in different lineages to carry out a particular function. This might reflect pressures to overcome female resistance to more ancestral versions of SFPs. In this sense, the apparent complexity of seminal fluid may reflect previous conflicts. Finally, an aspect of the complexity of the action of SFPs is that they can, and often do, involve obligate participation of female molecules. Three examples, from Drosophila, are that (1) ovulin processing cannot be completed without female contributions (Park and Wolfner 1995; Heifetz et al. 2005; Ravi Ram et al. 2006; LaFlamme et al. 2012, 2014); (2) the effects of a sperm-bound seminal protein (sex peptide $[\mathrm{SP}]$ ) require at least four female-expressed genes (Yapici et al. 2008; Findlay et al. 2014); and (3) SFPs such as ovulin act by turning up (or on) physiological pathways within females (Rubinstein and Wolfner 2013). That certain SFPs interact in molecular pathways with female proteins may constrain the evolution of those SFPs. Moreover, the existence of such con- straints could open the door for other SFPs to evolve to target the pathway in other ways but with the same overall effect on the female.

It is also important to note that there are other, nonproteinaceous molecules in seminal fluid that could be players in postmating sexual conflict (e.g., steroid hormones [Baldini et al. 2013], juvenile hormone in insects [Borovsky et al. 1994; Clifton et al. 2014], prostaglandins [Destephano et al. 1974; Loher et al. 1981; Robertson 2007], vesicles [Leiblech et al. 2012; Aalberts et al. 2013], and noncoding RNAs such as miRNAs [e.g., Li et al. 2012]). Much less is known about the evolution, identity, and function of these other molecules in comparison to SFPs, but their study promises a fruitful avenue for future research. It is possible that, in some species, these molecules play roles performed by SFPs in other species. It is tempting to speculate that such a situation might, in part, contribute to interspecific differences in the SFP composition and complexity.

\section{DO SFPs CONTRIBUTE TO POSTMATING SEXUAL CONFLICT?}

SFPs may serve as biochemical and physiological agents that manipulate female behavior and physiology in ways that benefit males. Yet, females may also be taking advantage of SFPs as reliable cues for initiating physiological reproductive processes to coordinate with the receipt of sperm (Chapman 2001; Ratto et al. 2012; Baldini et al. 2013). Below, we present the processes over which postmating conflict is predicted to occur and the evidence for roles of SFPs in each; these ideas are summarized in Table 1.

\section{Remating}

Females of many insect species show dramatic changes in postmating behavior (reviewed in Gillott 2003; Sirot et al. 2009; Avila et al. 2011). In some species, mated females do not remate, or they remate at very low levels. These changes in female mating propensity could be advantageous to both sexes by reducing the risk of further sperm competition to males and reducing the costs of mating to females. However, 
Table 1. Summary of potential conflicts mediated by SFPs

\begin{tabular}{|c|c|c|}
\hline $\begin{array}{l}\text { Trait over which } \\
\text { there is potential } \\
\text { conflict }\end{array}$ & Nature of the potential conflict & $\begin{array}{c}\text { Types of SFPs that are } \\
\text { potentially responsible for } \\
\text { the conflict }\end{array}$ \\
\hline Remating & $\begin{array}{l}\text { Conflict over remating may occur between a female and her } \\
\text { previous mates and between a mated female and } \\
\text { courting males. Remating may benefit the female but at a } \\
\text { cost to her previous mates because there are potential } \\
\text { benefits for females of topping up or receiving better- } \\
\text { quality, fresh sperm. These benefits may be at odds with } \\
\text { the interests of males whose sperm are already in storage. } \\
\text { There are also potential conflicts arising from the } \\
\text { deleterious effects of male-male sperm competition. } \\
\text { Yet, extensive remating could be costly to a female but } \\
\text { beneficial to the males attempting to mate with her. }\end{array}$ & $\begin{array}{l}\text { Those that modulate female } \\
\text { receptivity, attractiveness, } \\
\text { activity levels, pheromone } \\
\text { production, and emission }\end{array}$ \\
\hline $\begin{array}{l}\text { Sperm transfer, } \\
\text { storage, } \\
\text { retention, } \\
\text { usage }\end{array}$ & $\begin{array}{l}\text { Conflict may arise over how many sperm are transferred } \\
\text { during mating, stored by the female, and released for } \\
\text { fertilization. The interests of the sexes over the efficiency } \\
\text { of individual sperm usage should be aligned. However, } \\
\text { sperm usage may become inefficient as a result of } \\
\text { elevated rates of egg production, over which there is } \\
\text { separate potential conflict, see below. }\end{array}$ & $\begin{array}{l}\text { Those that mediate sperm } \\
\text { transfer, sperm storage, } \\
\text { sperm competition, the } \\
\text { musculature of the female } \\
\text { reproductive tract, } \\
\text { including the sperm } \\
\text { storage organs }\end{array}$ \\
\hline $\begin{array}{l}\text { Egg production, } \\
\text { ovulation, egg } \\
\text { provisioning, } \\
\text { oviposition }\end{array}$ & $\begin{array}{l}\text { Males may often gain from elevating current egg-production } \\
\text { or egg-provisioning rates more than is the case for females. } \\
\text { Females may trade off current versus future investment } \\
\text { and gain from a longer-term strategy. Males, on the other } \\
\text { hand, may gain from increased current investment by the }\end{array}$ & $\begin{array}{l}\text { Those that mediate } \\
\text { ovulation, release of } \\
\text { reproductive hormones, } \\
\text { egg production, and } \\
\text { provisioning }\end{array}$ \\
\hline
\end{tabular}
female, despite any future costs. Any divergence over the rate of ovulation may negatively impact the efficiency of fertilization, as noted above.

Food intake Females may need to increase or change their nutrient intake to support increased reproductive rate. This will be favored in an open-ended way by males, who may have little interest in any future costs that the female might incur. However, increased nutrient trafficking decreases female life span, thus representing potential sexual conflict in terms of a female's future reproductive capacity.

Activity The female's sleep/wake cycles can be altered by SFPs and could impact energy usage. Increased activity and reduced siesta sleep in females (e.g., in Drosophila) could incur long-term costs for females but not males, reflecting a potential conflict.

Immune Striking changes to the immune system occur during activation reproduction, the significance of which is not yet globally clear. However, there is potential for conflict if there is a suboptimal under- or overexpression of immunity in the female, with immune activity traded off against future reproductive capacity.

Life span

SFPs that reduce female life span can be selected because any cost is incurred in the future. Therefore, the effect of such costs is felt unequally by males and females.

Those that mediate feeding behavior and nutrient balancing

Those that mediate activity patterns and circadian rhythms

SFPs that have antimicrobial activity or that cause the expression of immune genes in females

SFPs that either directly or indirectly exert costs leading to reduced female life span 
L.K. Sirot et al.

females may also experience costs from not remating, as this may prevent the acquisition from future mates of any direct (e.g., food or other resources) or indirect benefits (e.g., "better," more compatible, or diverse alleles for offspring). Furthermore, conflict over remating can also occur when males attempt to mate with previously mated females. Males that court and attempt to mate with unreceptive, recently mated females may experience the costs of courtship without the benefit of offspring production. Additional costs can also arise; for example, D. melanogaster males that are rejected when they attempt to mate with previously mated females are less likely to court the females that they subsequently encounter and regardless of whether those new females have mated (Siegel and Hall 1979).

SFPs influence female remating in a manner consistent with sexual conflict. In several insect species, receipt of SFPs decreases the probability of female remating (reviewed in Gillott 2003; Sirot et al. 2009; Avila et al. 2011). Initial decreases in remating may not involve SFPs and can result from processes such as transfer of cuticular pheromones (e.g., in Drosophila [Zawistowski and Richmond 1986]) or from physical mate guarding. Longer-term changes in female receptivity across a wide range of insects, however, derive from the actions of SFPs (reviewed in Gillott 2003; Arnqvist and Rowe 2005; Avila et al. 2011). In species that form mating plugs, specific mating plug proteins (e.g., PEB2 in Drosophila) can increase latency to remating in females (Bretman et al. 2010). In all cases in which SFPs influence female remating, they appear to decrease the probability or frequency of remating. Thus far, little is known about the role of female-derived molecules. One exception, however, is the sex peptide receptor (SPR) of D. melanogaster (Yapici et al. 2008). SPR is a G-protein-coupled receptor, and its activity in a set of reproductive tract neurons in the female is necessary for sex peptide (SP), a 36-amino-acid peptide with diverse phenotypic effects (Chen et al. 1988; Kubli 2003), to suppress receptivity through activation of SPR (Hasemeyer et al. 2009; Yang et al. 2009). The ortholog of SPR in Helicoverpa armigera is also essential for female postmating responses such as pheromone production (Fan et al. 1999; Hanin et al. 2012). Recent studies suggest that there may be additional receptors for SP, and that SPR may facilitate access of SP to the nervous system (Ja et al. 2009; Haussmann et al. 2013). Additional female-encoded molecules have been identified that are also essential for SP effects (including on receptivity [Findlay et al. 2014]). Furthermore, recent evidence from Drosophila suggests that there are female reproductive proteins that promote rapid remating (Sirot et al. 2014). This finding is consistent with the hypothesis that females are in conflict with their mates over the frequency of remating.

\section{Sperm Transfer, Storage, Retention, and Usage}

Females of all internally fertilizing animals store the sperm that they receive during mating (Neubaum and Wolfner 1999), for days (e.g., most mammals), weeks (e.g., Drosophila [Neubaum and Wolfner 1999]; some birds [Sasanami et al. 2013]), or even years (e.g., some Hymenoptera and reptiles [Gist and Congdon 1998]). Sperm are stored in females in specialized organs (e.g., spermathecae, seminal receptacles in insects [Neubaum and Wolfner 1999]) or in special regions of the reproductive tract (e.g., isthmus in mammals [Suarez 2008]) and their release must be coordinated with the opportunity to encounter eggs. Storage of sperm is potentially advantageous to both sexes by allowing for extended progeny production after mating. However, it also provides the opportunity for conflicts, such as those resulting from cryptic female choice and sperm competition. Moreover, there could be sexual conflict over which sex controls the rate of sperm release. For example, it might be beneficial for the female to replace older sperm with newer, fresher sperm or sperm from a better quality male (e.g., Lüpold et al. 2013). This would be at odds with the male's interest in maintaining his own sperm in storage so they can be used for fertilization. It might also be advantageous to the female to modulate the rate of sperm release to coordinate with the timing of egg production, whereas it 
might benefit the male to have his sperm used in fertilizations as quickly as possible.

SFPs play important roles in the transit of sperm into storage. For example, transglutaminases - the cross-linking enzymes in the seminal fluid of mice (Dean 2013) and anopheline mosquitoes (Rogers et al. 2009)_are necessary for the coagulation of seminal fluids and the consequent efficient movement of sperm to storage sites. An SFP in D. melanogaster (Acp36DE) is necessary to regulate the uterine contractions that move sperm into storage (Avila and Wolfner 2009). SFPs in bovine seminal plasma bind to sperm (Gwathmey et al. 2006) and to annexins (Ignotz et al. 2007) on the oviductal epithelium. This binding allows sperm to be stored in the cows' sperm reservoirs. SFPs also are important in regulating the release of sperm from storage for fertilization. In Drosophila, the lectin Acp $29 A B$ is required for maintenance of sperm in the female's storage organs (Wong et al. 2008), and SP is required for efficient rate of release of sperm from storage in mated females (Avila et al. 2010). Furthermore, several other SFPs are necessary to transport SP to the necessary location to exert its effects. In cows, SFP-mediated release of sperm from storage allows the sperm to move to the fertilization site (Hung and Suarez 2010). During the process of sperm storage, SFPs have the potential to directly affect the sperm of a female's previous mates. In vitro studies in Hymenoptera (den Boer et al. 2010) and Diptera (Holman and Snook 2008) show that incubating sperm in SFPs affects their viability. In Hymenoptera, SFPs from one male can decrease the viability of rival males' sperm and thus the ability of those sperm to successfully fertilize eggs (den Boer et al. 2010). In sum, SFPs affect the ability of a male's sperm to survive and travel to the appropriate storage sites to be stored, retained, and released for fertilization (Xue and Noll 2000). They can also negatively impact the survival or success of competitor sperm in the female. In this capacity, SFPs can play important roles in sexual conflict over sperm use patterns (also see work by Edward et al. 2014).

A female may also benefit by influencing sperm use patterns (Eberhard 1996). This phenomenon may be mediated by female-derived molecules. Hymenopteran female spermathecal secretions can act to diminish male-male conflicts by countering the negative viability effect of seminal fluid on the sperm of different males (den Boer et al. 2009). This pattern could be consistent with an intense "conflict phase" between the males followed by a subsequent dampening down of conflict in order for the female to retain viable sperm for a long time, hence prolonging progeny production over an extended period. In addition, several lines of evidence suggest that females play a physically active role in influencing sperm use patterns. For example, genetic evidence and allelic correlations to sperm competition outcomes indicate that in D. melanogaster, a functioning female nervous system is necessary for proper sperm storage or to influence the outcome of sperm competition (Arthur et al. 1998; Chow et al. 2013). In another example, sperm storage is compromised in dead or anesthetized Tribolium castaneum females, again suggesting an active role for the female in sperm management (Bloch Qazi et al. 1998).

\section{Egg Production}

The reproductive success of both sexes depends largely on the quantity and quality of fertilized eggs. The female has to make eggs that are provisioned for future embryonic development, release them from the ovaries (ovulation), and move them through the reproductive tract to the correct location for further development (either inside or outside of the female, depending on the species). We consider these events together as the "egg-production process" (see Heifetz et al. 2000). In species with little or no oogenesis, ovulation or (if appropriate) egg laying before mating, egg production must increase after mating.

Increased egg production should benefit both female and male if more progeny are produced. In an additional benefit to the female, by coupling her level of egg production to mating, she does not "waste" resources making eggs when she lacks sperm to fertilize them. Once she has mated, however, it pays to increase egg production (all steps) because those eggs can be 
L.K. Sirot et al.

fertilized. Yet, even these apparently mutually beneficial changes may engender potential conflicts: Mating may induce a higher short-term level of egg production in the female than that which maximizes her lifetime reproductive success. Females risk trading off resources that they might otherwise have used for defense against pathogens or for other survival traits. Furthermore, in species that lay eggs, oviposition can be costly to females in terms of time allocation, energy expenditure, and exposure to predators and parasites. Thus, the optimal rate of egg production is a source of sexual conflict.

Ovulation frequency is perhaps a less obvious arena than overall egg production for sexual conflict (particularly in mammals without induced ovulation, in which ovulation does not increase after mating). Ovulation could, however, be a source of sexual conflict in insects (and potentially in mammals who are induced ovulators; e.g., camelids [Adams and Ratto 2013]). For example, in Drosophila, the buildup of many mature (but unovulated) oocytes in the ovaries of unmated females feeds back to arrest oogenesis (Chapman et al. 2001; DrummondBarbosa and Spradling 2001). So, males could benefit by increasing ovulation rates, thereby relieving this feedback inhibition and thus accelerating the increase in oogenesis. The resulting increased egg production can exert a physiological cost on females and thus, as noted above, represents a source of sexual conflict.

In insects, SFPs influence the egg-production process, at several stages (reviewed in Gillott 2003; Arnqvist and Rowe 2005; Avila et al. 2011). For example, D. melanogaster SP increases the number of eggs made, consistent with its effects in raising juvenile hormone titers (Moshitzky et al. 1996), and also through effects on specific neurons that innervate the reproductive tract (Hasemeyer et al. 2009; Yang et al. 2009). D. melanogaster SP can also increase egg production in the moth $H$. armigera on injection (Fan et al. 2000), and knockdown of the $H$. armigera ortholog of the sex peptide receptor blocks postmating increases in egg production (Hanin et al. 2012). In D. melanogaster, an SFP has been identified (ovulin) that increases ovulation rate specifically (Herndon and Wolfner 1995; Heifetz et al. 2000). Increased ovulation triggered by SFPs is not, however, restricted to insects. For example, although many mammals are spontaneous ovulators (i.e., independent of mating or SFPs), camelid ovulation is induced by the nerve growth factor in seminal fluid (Kershaw et al. 2012; Ratto et al. 2012), analogous in outline to the situation found in Drosophila. Therefore, through their effects on egg production and release, SFPs may mediate conflict over these steps in the egg-production process.

Recent evidence from dipteran insects has provided insights into how seminal fluid molecules interact with female molecules to influence specific steps in egg production. For example, $D$. melanogaster ovulin stimulates ovulation by increasing the amount or activity of a femalederived neuromodulator (octopamine) that modulates muscle contractions that accompany ovulation (Rubinstein and Wolfner 2013). In the mosquito, Anopheles gambiae, a seminal fluid derived hormone induces increased production of a female reproductive tract protein that is necessary for mating-induced changes in egg development (Baldini et al. 2013). Such molecular interactions between male- and female-derived molecules provide opportunities for both partners to adjust egg-production rate toward their own optima and, therefore, create an opportunity for sexually antagonistic coevolution.

\section{Food Intake and Processing}

The nutritional needs of females change once they are reproductively active. For example, in arthropods, the increased production of eggs requires increased food resources to provide and sustain energy. In mammals, the physiological demands of pregnancy also impact the amount of food needed by the female. Consistent with the idea that increased egg production requires additional resources, mating can alter food preferences in arthropods. Mated D. melanogaster females eat more protein (Ribeiro and Dickson 2010), mated Aedes aegypti mosquito females take larger blood meals (Houseman and Downe 1986), and a male-derived factor stimulates blood feeding and engorgement in ticks 
(Weiss and Kaufman 2004; Donohue et al. 2009).

Conflicts may occur in this arena as well. For example, it could be beneficial to the male to increase food consumption by his mate if it allowed her to produce more eggs and hence more progeny. But increased food consumption is associated with a decrease in longevity (in flies, nematodes, and mice [Chapman and Partridge 1996; Partridge and Gems 2002; Gems and Partridge 2013]) and thus may be costly to the female. In addition, the increased time spent eating, or finding different food sources, can potentially expose females to predation and pathogens, providing additional potential sources of conflict.

The role of SFPs in feeding related processes is clear in some insects. For example, receipt of SP increases the amount of food consumed by D. melanogaster females (Ribeiro and Dickson 2010) and changes the female's food preferences. SP also affects the rate of intestinal transit, with mated $D$. melanogaster females having slower intestinal transit than virgins, producing more concentrated excreta, presumably because they have absorbed more water (and nutrients) from their food (Cognigni et al. 2011; ApgerMcGlaughon and Wolfner 2013). In contrast, mated female Ae. aegypti mosquitoes digest their blood meals more rapidly than virgins, an effect that has also been attributed to SFPs (Downe 1975).

\section{Activity Level}

Mated D. melanogaster females sleep less and move around more than do unmated females (Isaac et al. 2010). This postmating response, dependent on SP, also could result in conflict. The additional movement could be detrimental for females by decreasing their regenerative sleep time, taking energy that could be used for somatic maintenance or to produce eggs, and potentially exposing them to predation. In the tephritid fruit fly (Ceratitis capitata), mating (or injection with seminal fluids) changes the attraction of females from a preference for male odors to a preference for fruit used for oviposition (Jang 1995). Similarly, in the mosquito
Ae. aegypti, mated females are less likely than unmated females to fly toward a host. Injections of male accessory glands into unmated females decrease their response to host cues, suggesting this change is mediated, in part, by seminal fluid molecules (Fernandez and Klowden 1995). Consistent with this hypothesis, male Ae. aegypti transfer an SFP that can change host-seeking behavior when applied topically to females (Naccarati et al. 2012).

\section{Immune Activation}

Mating causes changes in immune capacity in a number of animals, although the ultimate reasons are as yet poorly understood. Immune changes could protect the female from microbes introduced during mating, could reflect tradeoffs occasioned by the need to produce eggs (insects), or could lessen the probability of rejecting the fetus (mammals). These changes provide another arena for conflict; whatever benefits changes in immunity might have for male (or female) fertility might be accompanied by negative effects on the female's immune capacity or by trade-offs with other physiological processes. For example, a Drosophila female's immunity to systemic infection drops after mating (Fedorka et al. 2007; Short and Lazzaro 2010; but see also Zhong et al. 2013) and upregulation of female immunity has been proposed to generate a hostile environment for sperm. That seminal fluid plays a role in mating related immunity is known in Drosophila, mice, and humans (Robertson et al. 2009; Guerin et al. 2009, 2011; Sharkey et al. 2012; Short et al. 2012), and seminal fluid of all animals tested to date includes predicted antimicrobial compounds (e.g., see Poiani 2006; Avila et al. 2011). The effect of SFPs on immunity is complex, at least in Drosophila. Although numerous studies have indicated that mating, and SFPs in particular, induce an increase in expression of antimicrobial peptide (AMP) genes, or in AMP production, mated female Drosophila show an SFPinduced decrease in systemic immunity after mating (Short et al. 2012). It is possible that there are tissue-specific differences in immune response to mating - perhaps the AMPs protect 
L.K. Sirot et al.

the reproductive tract at the expense of systemic immunity.

\section{Life Span}

Reductions in life span associated with elevated reproduction are common in both sexes, but the nature of those costs often differs substantially between males and females. Sexual conflict can occur because adaptations that increase the reproductive success of males can be selected even if they also cause decreased life span in females, and vice versa. Females are expected to, and indeed do, have the capacity to evolve to ameliorate these costs. This leads to adaptation and counter adaptation (i.e., sexually antagonistic coevolution).

Laboratory experimental evolution in D. melanogaster provides some support for the idea that sexual conflict can be manipulated experimentally, over evolutionary time, with predictable outcomes for life span. For example, the level of sexual conflict can be manipulated in the laboratory by altering sex ratios. A high ratio of males to females is expected to increase the opportunity for sexual conflict over the optimum value of reproductive traits such as the frequency of mating in this species. In populations of $D$. melanogaster evolving under conditions with elevated potential for sexual conflict (arising from increased mating frequency), females evolved to live longer in the presence of males (Wigby and Chapman 2004). This suggests that females evolved resistance to the harmful (i.e., life-span-shortening) effects of elevated mating frequency. The evidence that females can evolve to minimize male-imposed costs suggests the strong potential for sexual conflict, in particular over optimum female life span. In terms of corresponding male adaptations, there are conflicting reports, with either no differences in male-induced harm (Wigby and Chapman 2004) or reduced harm under low-conflict conditions (Nandy et al. 2013). Experiments in which selection is limited to males, which predict the evolution of male benefit phenotypes, have also given various results. Rice (1998) reported the evolution of increased male harm under male limited selection, where- as Jiang et al. (2011) found no changes, using the same approach and source population. However, to date no study has explicitly examined the effects of SFPs on the evolution of male harm (or female resistance). That such effects might be mediated by SFPs is suggested by the finding that experimental evolution under altered adult sex ratios (and hence opportunities for sexual conflict) can result in divergent ejaculate allocation strategies (Linklater et al. 2007).

SFPs are thought to be involved in the conflict between adaptations that increase male reproductive success and decrease female life span because receipt of high levels of SFPs can be costly to females, causing a decrease in female longevity and reproductive success (Chapman et al. 1995). The shortening of female life span in response to SFPs could be a side effect of SFP function (e.g., of increased male permating fitness or a direct "toxic" effect that is selected to reduce the likelihood of female remating and/ or to increase current investment in reproduction (Johnstone and Keller 2000; Lessells 2005). Support for the "side effect" idea comes from data that some SFP-mediated fitness traits are directly linked to reductions in female life span. Such a relationship is observed between increased male sperm defense (success of a first mating male after subsequent matings) and early female mortality in D. melanogaster (Civetta and Clark 2000). Furthermore, SFPs with identified or predicted reproductive functions that benefit males are implicated in causing female mating costs in Drosophila (SP [Wigby and Chapman 2005]) or have been suggested to play such a role (e.g., SP, CG8137, and CG10433 [Mueller et al. 2007]; Acp62F [Lung et al. 2002; Civetta et al. 2005]). However, the situation may be complex, as a recent study in $D$. melanogaster found no evidence that elevation of sexual conflict, via increased male to female sex ratio, affected the frequency of a null allele of Acp62F (Wong and Rundle 2013).

Evidence for the idea that SFPs are directly selected to be "toxic" is difficult to gather unambiguously, as the toxic effect must be linked to some male benefit (otherwise it would not be selected). One possible line of evidence for a direct toxic effect of SFPs would be if the toxic- 
ity occurred via a different pathway from the effect of the SFP on male reproductive success. To our knowledge, however, there is little evidence for this possibility. Although the toxicity of ectopic expression of SFPs (e.g., Lung et al. 2002; Mueller et al. 2007) could represent such evidence, it must be noted that that the ectopic expression was at very high levels in those experiments. Studies are needed in which potential toxicity of these SFPs is measured in situations in which their ectopic expression is at levels closer to those delivered during mating.

It should also not be ruled out that longevity "costs" may be lower than first perceived if there are beneficial effects of SFPs on females earlier in their lives. Although no such benefits have yet clearly been identified (e.g., Brommer et al. 2012), costs to females could be lowered if SFPs caused early life egg production to increase, minimizing the fitness effect of life span reduction (Edward et al. 2011). Males may also suffer longevity costs from ongoing SFP-related sexual conflict. For example, if females evolve decreased sensitivity to SFPs, selection may act on males for increased SFP production, which, in turn, could result in decreased male life span. So far, this prediction has not been tested. The finding that males that invest in longer matings throughout their lives can suffer reduced life span and late life mating capacity (Bretman et al. 2013) suggests that such effects could occur.

\section{DOES SEXUAL CONFLICT SHAPE SFP EVOLUTION?}

Sexual conflict can occur in two modes-intraand interlocus; these terms define whether the conflict occurs between the same or different loci, respectively. Sexual conflict mediated by SFPs is likely to be exclusively in the interlocus mode, because SFPs generally interact with non-SFP proteins encoded by different loci (including female-encoded proteins) to influence the outcome of male-female encounters (e.g., timing or amount of remating or egg production). If SFPs participate in ongoing sexual conflicts described above (see the section Do SFPs Contribute to Postmating Sexual Conflict?), then the genes that encode them should show evidence of sexually antagonistic selection. This evidence could include changes in sequence or expression level between the interacting loci. These changes, in turn, could result in modifications in seminal fluid composition over time (Perry et al. 2013).

\section{Molecular Signatures of Conflict}

A general prediction (Parker 1979) is that sexual conflict can, under some conditions, lead to continual evolutionary chases between the adaptations in one sex and the counteradaptations in the other (Tregenza et al. 2006). Such chases can result in coevolution between the genes in males and females that encode these adaptations and counteradaptations. This coevolution could involve changes in protein sequence or in expression level of genes subject to sexual conflict. Theory predicts that this type of coevolution between males and females can lead to diversification in the sequences of the interacting loci involved. If this diversification occurs in reproductive genes in individuals from different populations of the same species, it can facilitate reproductive isolation between populations, and ultimately speciation, owing to breakdown in reproductive processes. Dynamic change in expression levels could also result in rapid diversification between different populations if it promoted regulatory incompatibilities between the reproductive genes of individuals from different populations. However, this possibility has not yet been considered in any detail.

Theory since Parker's original formulation (Parker 1979), from simple to multilocus models, quantitative to explicit genetics, predicts that sexual conflict can lead to five different types of dynamic outcomes between interacting loci in males and females (Parker 1979; Frank 2000; Rowe et al. 2003, 2005; Gavrilets and Hayashi 2005; Hayashi et al. 2007). These outcomes are continuous evolutionary chases, cyclic coevolution, evolution toward an equilibrium, differentiation in female traits, and differentiation in male and female traits (Fig. 2). In addition, females could vary in their sensitivity to SFPs (or in their activation threshold to SFPs). Theory predicts that when this occurs female 
L.K. Sirot et al.

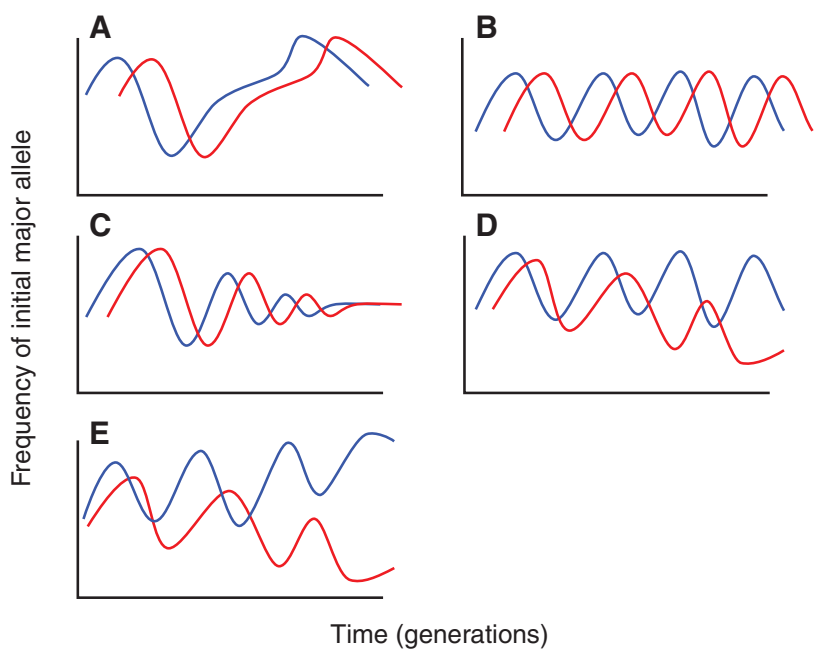

Figure 2. The simplified dynamic outcomes of sexual conflict between SFPs and their receptors in females, based on data adapted from the predictions of Parker (1979) and Hayashi et al. (2007). In this case, sexually antagonistic coevolution is occurring between different loci in males and females, each with two alleles. The frequency of the initial most frequent allele for each of the loci in males (blue) versus females (red) is shown. $(A)$ A continuous coevolutionary chase, in which the frequency of the female allele tracks that of the male, with no underlying pattern, through time. (B) Cyclic coevolution, in which the female allele frequency tracks that of the male, with the coevolution having a cyclical pattern through time. $(C)$ Evolution toward an equilibrium, in which the frequency of the female allele tracks that of the male toward a stable invariant frequency. (D) Differentiation in female, but not male allele frequency (an example of Buridan's ass). Here, the frequency of the major male allele continues to fluctuate through time, but that of the female, though initially tracking that of the male, diverges and in this case significantly decreases in frequency. Therefore, the coevolution has led to divergence in the frequencies of the two female alleles. $(E)$ Differentiation in male and female allele frequencies. The frequency of the major male and female alleles initially show coevolutionary fluctuations; however, over time there is divergence in the frequency of both male and female alleles, with, in this case, the initial major allele in males becoming more frequent and that of the female becoming less so. Therefore, the initial coevolution has led to divergence in the frequencies of the two male and the two female alleles.

traits can evolve to "ignore" male adaptations to sexual conflict (Rowe et al. 2005). For example, females might become completely resistant to a male SFP that induces high levels of egg production. Expression level variation could mediate this type of regulatory change (e.g., through down-regulation of a female receptor).

To date, four kinds of evidence for signatures of sexual conflict have been described.

\section{(i) Rapid Evolution, in Sequence or Regulation, in Some SFP Loci and Their Receptors in Females}

Sexual conflict involving SFPs is expected to result in selection for male molecules with increasingly "manipulative" (male benefit/female detriment) functions, and for female SFP receptors to become more resistant to the effects of such SFPs (Rice 1996; Pitnick et al. 2001). We would therefore expect rapid sequence and/or expression changes in these molecules. There is substantial evidence for rapid SFP evolution, both at the sequence level and with respect to seminal fluid composition. Sequence-based studies in a wide range of species, including insects (e.g., Aguadé et al. 1992; Swanson et al. 2001; Begun et al. 2000) and mammals (Ramm et al. 2008, 2009; Karn et al. 2008), have identified SFP loci that diverge rapidly between species and/or whose patterns of sequence evolution are indicative of positive selection. Furthermore, in lineages for which genome-wide evolutionary comparisons have been performed, SFPs are typically found to evolve more rapidly, on average, than 
other functional classes of protein (e.g., Clark and Swanson 2005; Haerty et al. 2007; Dean et al. 2009; Findlay and Swanson 2010; Wong 2010). Similarly, SF composition appears to change particularly rapidly in a number of species. For example, many genes encoding known SFPs in D. melanogaster are undetectable in other members of the genus (Mueller et al. 2005; Wagstaff and Begun 2005; Haerty et al. 2007), and novel species-specific SFP genes have been described in Drosophila (Wagstaff and Begun 2007; Findlay et al. 2008, 2009; Almeida and Desalle 2009). Systematic characterization of seminal fluid composition in other groups of animals (e.g., mammals) will help to determine the generality of this trend.

It is worth noting that, along with sequence level changes, there can also be significant variation in the expression level of SFP loci and of SFP receptors within and between populations (Smith et al. 2009; Ayroles et al. 2011). Studies of this type of variation in the context of sexual conflict have not yet been reported. The extent to which expression level variation occurs in genes encoding female proteins that interact with SFPs is of significant interest. It could, for example, represent some of the "missing" variation that is evident in comparisons between the rapid evolution of male-expressed SFPs versus the typically lower levels of sequence variation seen within the female-expressed loci with which SFPs potentially interact (e.g., Swanson et al. 2004; Prokupek et al. 2009). Females might respond to new SFP sequence variants by changing the expression level or sensitivity of existing receptors and interacting molecules. This could subsequently select for ever-newer SFP sequence variants in the male, or "improved" versions of old SFPs. We suggest that further work into the extent and significance of expression level variation in genes encoding SFPs and the female proteins with which they interact will prove very informative.

\section{(ii) Correlations between Rates of SFP Evolution and Mating Systems}

If the intensity of sexual conflict or sexual selection is responsible for driving the rapid evolu- tion of SFP loci, this would predict a correlation between measures of the intensity of postcopulatory selection (such as mating system) and rate of SFP evolution. Mating system can be a good proxy for tests of such correlations because the intensity of postcopulatory sexual selection is generally expected to increase with female promiscuity. A number of studies have sought to test these ideas, and specifically, the hypothesis that rates of SFP sequence evolution should correlate with measures of female promiscuity and/or sperm competition risk. The results of these studies are, however, mixed. Some SFP genes show clearly elevated rates of amino acid substitution in species in which females mate with many males ( polyandry); however, many SFP loci do not show this pattern (reviewed in Wong 2011; see also Claw 2013; Schumacher et al. 2014). The reason for this inconsistency could be that the strength of selection may not be consistent for the same SFP across multiple species, perhaps because different signals and pathways may operate in different lineages. This would obscure correlations between mating system and SFP evolution in studies that focus on a few or single loci. This problem could be avoided if the average rates of evolution for multiple SFPs in monandrous versus polyandrous species were compared. Such analyses should include investigations of sequence variation across different members of the same biochemical gene family. This can reveal whether different family members are coopted for similar functions in different species. Studies using these approaches and including multigene comparisons report a higher average rate of evolution for testis-biased or testis-specific genes in chimpanzees (in which sperm competition is more intense) in comparison to humans (Wong 2010; see Turner and Hoekstra 2008 for a similar comparison in rodents).

\section{(iii) Coevolution between the Genes Encoding Interacting Male and Female Proteins}

In addition to affecting the rate of sequence evolution of SFPs, sexual conflict is expected to result in the coevolution of SFPs and recep- 
L.K. Sirot et al.

tors in females. This process can be characterized by successive waves of directional selection or fluctuating selection, leading to continual evolutionary chases (Fig. 2). In the simplest scenario, in which sexual conflict is mediated by interactions between a single SFP and a single female receptor, it is expected that these two molecules should coevolve over time. Such signatures should, in theory, be detectable, given knowledge of pairs of loci in males and females that are subject to sexually antagonistic selection, and robust methods for identifying coevolution (Clark and Aquadro 2010; Findlay et al. 2014). Unfortunately, it has been difficult to test this prediction, because female receptors have been identified for only a very few SFPs (Yapici et al. 2008; Haussmann et al. 2013). In addition, there is a lack of population genomic studies targeted at detecting potentially divergent evolutionary trajectories between different populations of the same species.

Even when a receptor has been identified, detecting coevolution is not straightforward. For example, SPR, the D. melanogaster SP receptor, has nonreproductive ligands in addition to SP (the myoinhibitory peptides, MIPs [Kim et al. 2010; Poels et al. 2010; Vandersmissen et al. 2013]). This may constrain its ability to coevolve with SP potentially independent of whether it is subject to sexual conflict. Another confounding situation would occur if the receptor and ligand interact through molecular features that are not directly reflected in the primary amino acid sequence of either protein. For example, in cows, annexins in the oviducts interact with BSP seminal proteins to mediate sperm storage-but this molecular interaction involves the annexins binding to sugar (fucose) modifications on the BSPs-modifications that are added posttranslationally (Ignotz et al. 2007). Although it has not yet been possible to test the hypothesis of coevolution with SFPs and their receptors, some ideas of what might be found come from results on coevolving egg (vitelline envelope) and sperm ligand/receptor pairs in abalone (VERL and lysin, respectively [Clark et al. 2009]). VERL and lysin are in linkage disequilibrium, even though their loci are not physically linked. They also show evi- dence for coevolution at the intrapopulation and between-species levels (Clark et al. 2009), including correlated rates of amino acid substitution.

Sexually antagonistic interactions are, however, unlikely to be limited to the simple scenario above, in which the interaction is only between one SFP and its female receptor. For example, sexual conflict could be mediated by SFPs that do not have a receptor, as in coevolution between SFPs that coagulate to form a mating plug and the female proteases that degrade the plug. Conflicts could also be mediated through interactions between SFPs and female morphology or behavioral traits. This type of conflict could be evident, for example, in coevolution between mating plug-forming SFPs and female plug removal behaviors, or female genital tract morphology changes. Such female traits may indeed be easier to identify than SFP receptors themselves and should be more widely considered. A second example is that antagonistic interactions between males and females could be impacted by interactions of either sex with pathogens that access the reproductive tract or cells. There is evidence that some immunity genes evolve more rapidly in promiscuous species, consistent with the idea that multiple mating is associated with increased immune challenge (Wlasiuk and Nachman 2010). In such a situation, it could be difficult to differentiate antagonistic coevolution between SFPs and their receptors from antagonistic coevolution between female receptors and the pathogens. This would be particularly difficult if the pathogen interacted directly with the SFP receptor in the female, because coevolution between the female receptor and the pathogen could also "drag along" SFP coevolution to retain SFP function through the female receptor. The primary driving interaction in this scenario would be the host-pathogen interaction, not the male-female conflict. However, without knowledge of host-pathogen interactions, the correct explanation for any coevolutionary patterns observed between SFPs and receptors could be hard to pin down.

One outcome of sexual conflict, predicted by theory when the intensity of sexual conflict 
Sexual Conflict and Seminal Fluid Proteins

between males and females is relatively weak, is the differentiation of reproductive traits in one sex but not in the other (the so-called Buridan's ass outcome, Fig. 2) (Gavrilets and Waxman 2002; Parker 2006; Hayashi et al. 2007). If this process occurs within a species, it could assist in the evolution of divergent reproductive forms, and hence reproductive isolation via the sympatric mode (i.e., in the absence of physical barriers to gene flow [Gavrilets and Waxman 2002]). Interestingly, there is empirical evidence for Buridan's ass in the apparently antagonistic interactions concerning the speed and efficiency of sperm entry into the egg; this evidence concerns the abalone sperm protein lysin, and the egg protein VERL to which it binds, as discussed above (Clark et al. 2009). The empirical observation is that male-derived lysin has low genetic variability and hence shows little phenotypic variation, whereas its female partner VERL shows abundant polymorphism and manifests multiple different phenotypes in females, associated in some cases with incipient speciation. These data have been interpreted as evidence for Buridan's ass in that the invariant male lysin is "stranded" between the divergent female VERLs (Panhuis et al. 2006). A Buridan's ass situation appears to be a unique signature of sexual conflict. Further work will show whether this phenomenon is seen for SFPs.

It is important to note that, although each of the evolutionary patterns described so far could arise as a result of sexually antagonistic coevolution, none is a unique signature of sexual conflict, with the possible exception of the Buridan's ass scenario, as discussed above. As such, the presence or absence of rapid SFP evolution is consistent with sexual conflict but does not rule out other selective regimes. Furthermore, even where sexual conflict over a particular outcome (e.g., egg-laying rate or remating) is expected to result in coevolution between an SFP and its receptor, coevolution may be impeded by pleiotropy (where the loci involved have additional, potentially nonreproductive, functions) or if the conflict is mediated by multiple interacting loci. Thus, care must be taken in interpreting patterns of SFP molecular evolution in the light of sexual conflict.

\section{(iv) Chromosomal Distribution of SFP Loci}

In organisms with chromosomal-based sex determination, there is an inevitable asymmetry of passage of sex chromosomes through the sexes (see work by Mank et al. 2014). In XX/ female and $\mathrm{XY} /$ male systems, for example, $\mathrm{X}$ chromosomes are present more often in females than in males. In such a situation, there is a greater chance for selection for genes of benefit to females on the $\mathrm{X}$ chromosome and less chance to select for genes of benefit to males. This would be predicted to lead to a situation in which female benefit genes should be X-enriched (Rice 1984). Consistent with this idea, the gene for SPR is X-linked in D. melanogaster. As additional SFP receptors are discovered it will be interesting to see whether they, too, are X-linked.

Genes encoding D. melanogaster SFPs are predominantly located on the autosomes. This could reflect that alleles of genes that more often benefit males can accumulate more easily on the autosomes, or perhaps that sex limitation in males is easier to evolve on autosomes, because of additional requirements for dosagecompensation control of X-linked genes in male Drosophila.

\section{Evidence for Conflict Resolution}

In addition to evidence for ongoing conflict mediated by SFPs, it should be possible to detect signatures of previous, but resolved, conflicts. These resolutions might, of course, themselves open up alternative possibilities, or routes for, novel sexual conflicts. Signatures of previous sexual conflict in the genome are predicted to be detectable as genomic "baggage" such as pseudogenes, gene redundancy, duplication, and/or gross genome rearrangements between sibling species. Examples of all of these phenomena are observed among genes encoding SFPs.

One line of evidence for resolution of conflict could be the loss of function of SFP genes, as females overcome or avoid their effects. The "lost" genes could be replaced by others, including by co-option of other members of the same biochemical family, in response. Such SFP 
L.K. Sirot et al.

turnover appears to be particularly rapid in Drosophila species subgroups and in the primate copulatory plug protein SEMG2 (Kingan et al. 2003; Carnahan and Jensen-Seaman 2008). Female gorillas, unlike their chimpanzee cousins, are usually monandrous during each reproductive bout, removing the opportunity for postcopulatory sexual conflict. Because primate copulatory plug proteins are thought to be maintained, at least in part, owing to the advantage they provide males in preventing sperm competition, in species with monandrous females, selection is expected to be relaxed on such proteins, and thus loss-of-function mutations within them would not be removed from the population (see also Claw 2013).

Resolution of one type of conflict can also provide conditions for new conflicts to emerge. For example, intralocus sexual conflict, which results from differing "demands" by males and females on a single gene, is often proposed to be resolved by the evolution of sex-limited expression of the relevant gene (see work by Ingleby et al. 2014). Sex limited expression for SFPs would have released SFPs from any functional constraint imposed by having to operate in females. It may also have allowed the effects of SFPs to be more easily tailored to coordinate reproductive processes. For example, an SFP signal from males received by females only once sperm transfer has been achieved would be an efficient way of activating reproductive processes in females at the correct time and in the correct sequence (Chapman 2001). This mechanism benefits both sexes. However, once present, sex limitation instantly opens up the possibility for relatively unconstrained direct manipulation of reproduction in the female by males, with the possibility of initiating a new interlocus sexual conflict. Hence, new routes for sexual conflict via the interlocus mode may emerge following resolution of intralocus sexual conflict via the evolution of sex limitation.

\section{CONCLUDING REMARKS}

SFPs provide an informative molecular system in which to study sexual conflict because they not only provide mechanisms that can underlie sexual conflict but also show signatures at the gene sequence and expression level of past and current conflict. In this section, we conclude by considering additional aspects of the interface between SFPs and sexual conflict and proposing future research directions.

\section{Is It All Conflict?}

The evidence provided in the sections above can be interpreted as indicating the presence of sexual conflict. However, we do not yet know to what extent conflict actually operates and how important it is in relation to processes such as sexual selection. As noted above (in the section The Potential Weapons), there are examples of biochemical pathways that include contribution by males and females (e.g. proteolytic processing of Drosophila ovulin, Fig. 1), males turning on molecular pathways in females (e.g., Rubinstein and Wolfner 2013), males activating already prepared pools of preexisting RNAs or proteins in females (e.g., Heifetz and Wolfner 2004; Lawniczak and Begun 2004; McGraw et al. 2004; Mack et al. 2006; Kapelnikov et al. 2008; Rubinstein and Wolfner 2013), and apparent male/female synergy in achieving sperm storage (e.g., Ignotz et al. 2007). These examples may reflect the requirement to coordinate the many complex processes needed in order for reproduction to be successful. It is worth considering, however, that sexual conflict can occur within even the most complex and apparently mutually beneficial of these interactions. SFPs have the potential to engage females in a "sensory trap" (West Eberhard 1979) through the use of SFP signals to which females "must" respond to reproduce successfully, but which can then be used to divert females from their optimal investment in reproduction. Females cannot evolve complete insensitivity; otherwise they achieve lower fitness (hence "trapped"). Only a combination of mechanistic knowledge with manipulative experiments can determine whether such a scenario exists.

Further, the intensity of sexual conflict mediated by SFPs may vary over time, both across and within generations. The intensity of conflict now may not indicate its relative importance in 
the past or future. Resource levels may also cause variability in the extent to which conflict is expressed (Fricke et al. 2010). For example, when food is scarce, females may be unable to exhibit increased egg laying following mating, no matter how much SF has been received. Additional experiments into the lifetime costs and benefits of SFP transfer from both the male and the female's perspective, made under a range of biologically relevant conditions, are now necessary to resolve the extent of sexual conflict mediated by SFPs.

\section{Practical Applications}

Understanding how SFPs shape and are shaped by sexual conflict has numerous potential practical applications, and also provides cautionary insights. For example, this knowledge could provide insights for the control of pest insects. One option for increased efficiency of insect control is to select for, or genetically engineer, males that have a greater effect on female reproductive physiology and/or behavior. This manipulation could be coupled with pest control strategies such as the sterile male technique or release of genetically modified strains that are altered in such a way to reduce damage (e.g., Fu et al. 2007). Proof of principle for the use of artificial selection in creating more "manipulative" males comes from studies in D. melanogaster. For example, female D. melanogaster mated to males that had experimentally evolved in a polygamous mating system took longer to remate and produced fewer offspring after mating than females mated to males that had evolved in a monogamous mating system (Holland and Rice 1999; Pitnick et al. 2001). Furthermore, D. melanogaster males selected for increased accessory gland size produced and transferred more SP and sired more offspring when in competition with other males than control males (Wigby et al. 2009). The results of these studies suggest that standard artificial selection could increase the ability of laboratory-reared males to induce postmating responses in their mates. Similar effects can be achieved simply by exposing males to rivals (Bretman et al. 2009). Selection or genetic engineering could be used to make SFPs more stable in females so that their effects persist, or to allow them to be effective even in the absence of sperm (in the case of SFPs, like SP, whose effects are sperm dependent). Another logical application of the use of SFPs in pest management would be to chemically interfere with the production of particular SFPs in males or their receptors in females. This approach may be successful for effects in females that are mediated by a single SFP-receptor pair, but as noted earlier there is significant redundancy in SFP functional classes and/or lack of specificity in SFP receptors that might make such interference with a single SFP or receptor less effective. Moreover, the rapid rate of SFP evolution suggests that pest species may evolve resistance to such strategies, as these strategies simulate what might happen under conflict scenarios. Rapid SFP evolution also makes it unlikely that SFP-based molecules used to target one species would negatively affect other species.

In addition to controlling pest populations, our knowledge of the role of sexual conflict in shaping SFPs could also inform strategies to promote successful reproduction outcomes in species of conservation concern, agricultural animals (e.g., honey bees and farm animals), and even humans. For example, for nonhuman animals, SFPs from males in populations in which females mate promiscuously may enhance the fertilizing ability of sperm used in assisted reproduction. Similarly, exposure of males to cues of sperm competition could increase the quantity or fertilizing ability of sperm in their ejaculates (Wedell et al. 2002; Killgallon and Simmons 2005; Bretman et al. 2009, 2011).

\section{Future Prospects}

SFPs are experimentally accessible molecules that exert precise and measurable effects on the female-yet are made by the male. These characteristics make them a fascinating and tractable system for dissecting molecular interactions that can participate in, and underlie, sexual conflict. In the sections above, we have highlighted some of these interactions and how 
L.K. Sirot et al.

they can contribute to or mediate sexual conflict. Here, we conclude by suggesting five areas of SFP research related to sexual conflict that are so far underexplored.

1. Identification of the SFP-interacting loci in females to conduct tests of coevolution and chromosomal distribution predictions.

2. Transcriptomic and proteomic studies of variation in SFP and receptor expression levels to identify previously unrecognized signatures of sexual conflict.

3. Genomic population studies in natural populations, analogous to those conducted for reproductive phenotypes (e.g., Andrés and Arnqvist 2001), to detect cycles of sexually antagonistic coevolution through time and space.

4. Studies of genome and expression level changes in response to experimental evolution under sexual conflict.

5. Cross-population and cross-species comparisons of SFP effectiveness in relation to the intensity of sexual conflict.

Future studies of the above areas, as well as continued dissection of how SFPs exert their effects on females, promise to reveal profound and fundamental insights into the evolutionary potential of conflict and cooperation between the sexes.

\section{ACKNOWLEDGMENTS}

We are grateful to Bill Rice, Larry Harshman, and two anonymous reviewers for valuable comments on this article and to Bill Rice and Sergei Gavrilets for the opportunity to write it. We thank the members of our laboratories for inspiration and helpful discussions. We appreciate support from National Institutes of Health (NIH) grants R01-HD038921 (to M.F.W.), R01HD059060 (to M.F.W.), R01-AI095491 (to M.F.W.); Natural Environment Research Council (NERC) and Biotechnology and Biological Sciences Research Council (BBSRC) grants (to T.C.); and a Natural Sciences and Engineering
Research Council (NSERC) Discovery Grant (to A.W.).

\section{REFERENCES}

${ }^{*}$ Reference is also in this collection.

Aalberts M, Stout TA, Stoorvogel W. 2013. Prostasomes: Extracellular vesicles from the prostate. Reproduction 147: R1-R14.

Adams GP, Ratto MH. 2013. Ovulation-inducing factor in seminal plasma: A review. Anim Reprod Sci 136: 148-156.

Aguadé M, Miyashita N, Langley CH. 1992. Polymorphism and divergence in the Mst26A male accessory gland gene region in Drosophila. Genetics 132: 755-770.

Almeida FC, Desalle R. 2009. Orthology, function and evolution of accessory gland proteins in the Drosophila repleta group. Genetics 181: 235-245.

Andrés JA, Arnqvist G. 2001. Genetic divergence of the seminal signal-receptor system in houseflies: The footprints of sexually antagonistic coevolution? Proc Biol Sci 268: 399-405.

Andrés JA, Maroja LS, Bogdanowicz SM, Swanson WJ, Harrison RG. 2006. Molecular evolution of seminal proteins in field crickets. Mol Biol Evol 23: 1574-1584.

Andrés JA, Maroja LS, Harrison RG. 2008. Searching for candidate speciation genes using a proteomic approach: Seminal proteins in field crickets. Proc Biol Sci 275: 1975-1983.

Apger-McGlaughon J, Wolfner MF. 2013. Post-mating change in excretion by mated Drosophila melanogaster females is a long-term response that that depends on sex peptide and sperm. J Insect Physiol 59: 1024-1030.

Arnqvist G, Rowe L. 2005. Sexual conflict. Princeton University Press, Princeton, NJ.

Arthur BI, Hauschteck-Jungen E, Naothiger R, Ward PI. 1998. A female nervous system is necessary for normal sperm storage in Drosophila melanogaster: A masculinized nervous system is as good as none. Proc Biol Sci 266: 1749-1753.

Avila FW, Wolfner MF. 2009. Acp36DE is required for uterine conformational changes in mated Drosophila females. Proc Natl Acad Sci 106: 15796-15800.

Avila FW, Ravi Ram K, Bloch Qazi MC, Wolfner MF. 2010. Sex peptide is required for the efficient release of stored sperm in mated Drosophila females. Genetics 186: 595600.

Avila FW, Sirot LK, LaFlamme BA, Rubinstein CD, Wolfner MF. 2011. Insect seminal fluid proteins: Identification and function. Annu Rev Entomol 56: 21-40.

Ayroles JF, Laflamme BA, Stone EA, Wolfner MF, Mackay TF. 2011. Functional genome annotation of Drosophila seminal fluid proteins using transcriptional genetic networks. Genet Res (Camb) 93: 387-395.

Baer B, Heazlewood JL, Taylor NL, Eubel H, Millar AH. 2009. The seminal fluid proteome of the honeybee Apis mellifera. Proteomics 9: 2085-2097.

Baldini F, Gabrieli P, South A, Valim C, Mancini F, Catteruccia F. 2013. The interaction between a sexually transferred steroid hormone and a female protein regulates 
oogenesis in the malaria mosquito Anopheles gambiae. PLoS Biol 11: e1001695.

Begun DJ, Whitley P, Todd BL, Waldrip-Dail HM, Clark AG. 2000. Molecular population genetics of male accessory gland proteins in Drosophila. Genetics 156: 1879-1888.

Bloch Qazi M, Aprille JR, Lewis SM. 1998. Female role in sperm storage in the red flour beetle, Tribolium castaneum. Comp Biochem Physiol A: Mol Integr Physiol 120: 641-647.

Borovsky D, Carlson DA, Hancock RG, Rembold H, van Handel E. 1994. De novo biosynthesis of juvenile hormone III and I by the accessory glands of the male mosquito. Insect Biochem Mol Biol 24: 437-444.

Bretman A, Fricke C, Chapman T. 2009. Plastic responses of male Drosophila melanogaster to the level of sperm competition increase male reproductive fitness. Proc Biol Sci 276: $1705-1711$.

Bretman A, Lawniczak MK, Boone J, Chapman T. 2010. A mating plug protein reduces early female remating in Drosophila melanogaster. J Insect Physiol 56: 107-113.

Bretman A, Gage MJ, Chapman T. 2011. Quick-change artists: Male plastic behavioural responses to rivals. Trends Ecol Evol 26: 467-473.

Bretman A, Westmancoat JD, Gage MJ, Chapman T. 2013. Costs and benefits of lifetime exposure to mating rivals in male Drosophila melanogaster. Evolution 67: 2413-2422.

Bromfield JJ, Schjenken JE, Chin PY, Care AS, Jasper MJ, Robertson SA. 2014. Maternal tract factors contribute to paternal seminal fluid impact on metabolic phenotype in offspring. Proc Natl Acad Sci 111: 2200-2205.

Brommer JE, Fricke C, Edward DA, Chapman T. 2012. Interactions between genotype and sexual conflict environment influence transgenerational fitness in Drosophila melanogaster. Evolution 66: 517-531.

Carnahan SJ, Jensen-Seaman MI. 2008. Hominoid seminal protein evolution and ancestral mating behavior. Am J Primatol 70: 939-948.

Chapman T. 2001. Seminal fluid-mediated fitness traits in Drosophila. Heredity 87: 511-521.

Chapman T, Partridge L. 1996. Female fitness in Drosophila melanogaster: An interaction between the effect of nutrition and of encounter rate with males. Proc Biol Sci 263: 755-759.

Chapman T, Liddle LF, Kalb JM, Wolfner MF, Partridge L. 1995. Cost of mating in Drosophila melanogaster females is mediated by male accessory gland products. Nature 373: $241-244$.

Chapman T, Herndon LA, Heifetz Y, Partridge L, Wolfner MF. 2001. The Acp26Aa seminal fluid protein is a modulator of early egg hatchability in Drosophila melanogaster. Proc Biol Sci 268: 1647-1654.

Chen PS, Stumm-Zollinger E, Aigaki T, Balmer J, Bienz M, Bohlen P. 1988. A male accessory gland peptide that regulates reproductive behavior of female $D$. melanogaster. Cell 54: 291-298.

Chow CY, Wolfner MF, Clark AG. 2013. A large neurological component to genetic differences underlying biased sperm use in Drosophila. Genetics 193: 177-185.

Civetta A, Clark AG. 2000. Correlated effects of sperm competition and postmating female mortality. Proc Natl Acad Sci 97: 13162-13165.
Civetta A, Montooth KL, Mendelson M. 2005. Quantitative trait loci and interaction effects responsible for variation in female postmating mortality in Drosophila simulans and D. sechellia introgression lines. Heredity 94: 94-100.

Clark NL, Aquadro CF. 2010. A novel method to detect proteins evolving at correlated rates: Identifying new functional relationships between coevolving proteins. Mol Biol Evol 27: 1152-1161.

Clark NL, Swanson WJ. 2005. Pervasive adaptive evolution in primate seminal proteins. PLoS Genet 1: e35.

Clark NL, Aagaard JE, Swanson WJ. 2006. Evolution of reproductive proteins from animals and plants. Reproduction 131: 11-22.

Clark NL, Gasper J, Sekino M, Springer S, Aquadro CF, Swanson WJ. 2009. Coevolution of interacting fertilization proteins. PLoS Genet 5: e1000570.

Claw KG. 2013. "Proteomic identification and evolutionary analysis of primate reproductive proteins," $\mathrm{PhD}$ thesis, University of Washington, Seattle.

Clifton ME, Correa S, Rivera-Perez C, Nouzova M, Noriega FG. 2014. Male Aedes aegypti mosquitoes use JH III transferred during copulation to influence previtellogenic ovary physiology and affect the reproductive output of female mosquitoes. J Insect Physiol 64: 40-47.

Cognigni P, Bailey AP, Miguel-Aliaga I. 2011. Enteric neurons and systemic signals couple nutritional and reproductive status with intestinal homeostasis. Cell Metab 13: 92-104.

Collins AM, Caperna TJ, Williams V, Garrett WM, Evans JD. 2006. Proteomic analyses of male contributions to honey bee sperm storage and mating. Insect Mol Biol 15: $541-$ 549.

Davies SJ, Chapman T. 2006. Identification of genes expressed in the accessory glands of male Mediterranean fruit flies (Ceratitis capitata). Insect Biochem Mol Biol 36: 846-856.

Dean MD. 2013. Genetic disruption of the copulatory plug in mice leads to severely reduced fertility. PLoS Genet 9: e1003185.

Dean MD, Clark NL, Findlay GD, Karn RC, Yi X, Swanson WJ, MacCoss MJ, Nachman MW. 2009. Proteomics and comparative genomic investigations reveal heterogeneity in evolutionary rate of male reproductive proteins in mice (Mus domesticus). Mol Biol Evol 26: 1733-1743.

den Boer SP, Boomsma JJ, Baer B. 2009. Honey bee males and queens use glandular secretions to enhance sperm viability before and after storage. J Insect Physiol 55: 538543.

den Boer SP, Baer B, Boomsma JJ. 2010. Seminal fluid mediates ejaculate competition in social insects. Science 327: 1506-1509.

Destephano DB, Brady UE, Lovins RE. 1974. Synthesis of prostaglandin by reproductive tissue of the male house cricket, Acheta domesticus. Prostaglandins 6: 71-79.

Donohue KV, Khalil SM, Ross E, Mitchell RD, Roe RM, Sonenshine DE. 2009. Male engorgement factor: Role in stimulating engorgement to repletion in the ixodid tick, Dermacentor variabilis. J Insect Physiol 55: 909-918.

Dottorini T, Nicolaides L, Ranson H, Rogers DW, Crisanti A, Catteruccia F. 2007. A genome-wide analysis in Anopheles gambiae mosquitoes reveals 46 male accessory gland 
L.K. Sirot et al.

genes, possible modulators of female behavior. Proc Natl Acad Sci 104: 16215-16220.

Downe AE. 1975. Internal regulation of rate of digestion of blood meals in the mosquito, Aedes aegypti. J Insect Physiol 21: 1835-1839.

Drummond-Barbosa D, Spradling AC. 2001. Stem cells and their progeny respond to nutritional changes during Drosophila oogenesis. Dev Biol 231: 265-278.

Eberhard WG. 1996. Female control: Sexual selection by cryptic female choice. Princeton University Press, Princeton, NJ.

Edward DA, Fricke C, Gerrard DT, Chapman T. 2011. Quantifying the life-history response to increased male exposure in female Drosophila melanogaster. Evolution 65: $564-573$.

* Edward DA, Stockley P, Hosken DJ. 2014. Sexual conflict and sperm competition. Cold Spring Harb Perspect Biol doi: 10.1101/cshperspect.a017707.

Fan Y, Rafaeli A, Gileadi C, Kubli E, Applebaum SW. 1999. Drosophila melanogaster sex peptide stimulates juvenile hormone synthesis and depresses sex pheromone production in Helicoverpa armigera. J Insect Physiol 45: 127-133.

Fan Y, Rafaeli A, Moshitzky P, Kubli E, Choffat Y, Applebaum SW. 2000. Common functional elements of Drosophila melanogaster seminal peptides involved in reproduction of Drosophila melanogaster and Helicoverpa armigera females. Insect Biochem Mol Biol 30: 805-812.

Fedorka KM, Linder JE, Winterhalter W, Promislow D. 2007. Post-mating disparity between potential and realized immune response in Drosophila melanogaster. Proc Biol Sci 274: 1211-1217.

Fernandez NM, Klowden MJ. 1995. Male accessory gland substances modify the host seeking behavior of gravid Aedes aegypti mosquitoes. J Insect Physiol 41: 965-970.

Findlay GD, Swanson WJ. 2010. Proteomics enhances evolutionary and functional analysis of reproductive proteins. BioEssays 32: 26-36.

Findlay GD, Yi X, Maccoss MJ, Swanson WJ. 2008. Proteomics reveals novel Drosophila seminal fluid proteins transferred at mating. PLoS Biol 6: e178.

Findlay GD, MacCoss MJ, Swanson WJ. 2009. Proteomic discovery of previously unannotated, rapidly evolving seminal fluid genes in Drosophila. Genome Res 19: 886896.

Findlay GD, Sitnik JL, Aquadro CF, Clark NL, Wolfner MF. 2014. Evolutionary rate covariation identifies new members of a protein network required for Drosophila female post-mating responses. PLoS Genet 10: e1004108.

Frank SA. 2000. Sperm competition and female avoidance of polyspermy mediated by sperm-egg biochemistry. Evol Ecol Res 2: 613-625.

Fricke C, Bretman A, Chapman T. 2010. Female nutritional status determines the magnitude and sign of responses to a male ejaculate signal in Drosophila melanogaster. J Evol Biol 23: $157-165$.

Fu G, Condon KC, Epton MJ, Gong P, Jin L, Condon GC, Morrison NI, Dafa'alla TH, Alphey L. 2007. Female-specific insect lethality engineered using alternative splicing. Nat Biotechnol 25: 353-357.
Gavrilets S, Waxman D. 2002. Sympatric speciation by sexual conflict. Proc Natl Acad Sci 99: 10533-10538.

Gems D, Partridge L. 2013. Genetics of longevity in model organisms: Debates and paradigm shifts. Annu Rev Physiol 75: 621-644.

Gillott C. 2003. Male accessory gland secretions: Modulators of female reproductive physiology and behavior. Annu Rev Entomol 48: 163-184.

Gist DH, Congdon JD. 1998. Oviductal sperm storage as a reproductive tactic of turtles. J Exp Zool 282: 526-534.

Guerin LR, Prins JR, Robertson SA. 2009. Regulatory T-cells and immune tolerance in pregnancy: A new target for infertility treatment? Hum Reprod Update 15: 517-535.

Guerin LR, Moldenhauer LM, Prins JR, Bromfield JJ, Hayball JD, Robertson SA. 2011. Seminal fluid regulates accumulation of $\mathrm{FOXP}^{+}$regulatory $\mathrm{T}$ cells in the preimplantation mouse uterus through expanding the FOXP3 $^{+}$cell pool and CCL19-mediated recruitment. Biol Reprod 85: 397-408.

Gwathmey TM, Ignotz GG, Mueller JL, Manjunath P, Suarez SS. 2006. Bovine seminal plasma proteins PDC-109, BSP$\mathrm{A} 3$, and BSP-30-kDa share functional roles in storing sperm in the oviduct. Biol Reprod 75: 501-507.

Haerty W, Jagadeeshan S, Kulathinal RJ, Wong A, Ravi Ram K, Sirot LK, Levesque L, Artieri CG, Wolfner MF, Civetta A, et al. 2007. Evolution in the fast lane: Rapidly evolving sex-related genes in Drosophila. Genetics 177: 1321-1335.

Hanin O, Azrielli A, Applebaum SW, Rafaeli A. 2012. Functional impact of silencing the Helicoverpa armigera sexpeptide receptor on female reproductive behaviour. Insect Mol Biol 21: 161-167.

Hasemeyer M, Yapici N, Heberlein U, Dickson BJ. 2009. Sensory neurons in the Drosophila genital tract regulate female reproductive behavior. Neuron 61: 511-518.

Haussmann IU, Hemani Y, Wijesekera T, Dauwalder B, Soller M. 2013. Multiple pathways mediate the sex-peptideregulated switch in female Drosophila reproductive behaviours. Proc Biol Sci 280: 20131938.

Hayashi TI, Vose M, Gavrilets S. 2007. Genetic differentiation by sexual conflict. Evolution 61: 516-529.

Heifetz Y, Wolfner MF. 2004. Mating, seminal fluid components, and sperm cause changes in vesicle release in the Drosophila female reproductive tract. Proc Natl Acad Sci 101: 6261-6266.

Heifetz Y, Lung O, Frongillo EA Jr, Wolfner MF. 2000. The Drosophila seminal fluid protein Acp26Aa stimulates release of oocytes by the ovary. Curr Biol 10: 99-102.

Heifetz Y, Vandenberg LN, Cohn HI, Wolfner MF. 2005. Two cleavage products of the Drosophila accessory gland protein ovulin can independently induce ovulation. Proc Natl Acad Sci 102: 743-748.

Herndon LA, Wolfner MF. 1995. A Drosophila seminal fluid protein, Acp26Aa, stimulates egg laying in females for one day after mating. Proc Natl Acad Sci 92: 1011410118.

Holland B, Rice WR. 1999. Experimental removal of sexual selection reverses intersexual antagonistic coevolution and removes a reproductive load. Proc Natl Acad Sci 96: 5083-5088. 
Holman L, Snook RR. 2008. A sterile sperm caste protects brother fertile sperm from female-mediated death in Drosophila pseudoobscura. Curr Biol 18: 292-296.

Houseman JG, Downe AER. 1986. Methods of measuring blood meal size and proteinase activity for determining effects of mated state on digestive processes of female Aedes aegypti (L.) (Diptera: Culicidae). Can Entomol 118: 241-248.

Hung PH, Suarez SS. 2010. Regulation of sperm storage and movement in the ruminant oviduct. Soc Reprod Fertil Suppl 67: 257-266.

Ignotz GG, Cho MY, Suarez SS. 2007. Annexins are candidate oviductal receptors for bovine sperm surface proteins and thus may serve to hold bovine sperm in the oviductal reservoir. Biol Reprod 77: 906-913.

* Ingleby FC, Flis I, Morrow EH. 2014. Sex-biased gene expression and sexual conflict throughout development. Cold Spring Harb Perspect Biol doi: 10.1101/cshper spect.a017632.

Isaac RE, Li C, Leedale AE, Shirras AD. 2010. Drosophila male sex peptide inhibits siesta sleep and promotes locomotor activity in the post-mated female. Proc Biol Sci 277: $65-70$.

Ja WW, Carvalho GB, Madrigal M, Roberts RW, Benzer S. 2009. The Drosophila G protein-coupled receptor, Methuselah, exhibits a promiscuous response to peptides. Protein Sci 18: 2203-2208.

Jang EB. 1995. Effects of mating and accessory gland injections on olfactory-mediated behavior in the female Mediterranean fruit fly, Ceratitis capitata. J Insect Physiol 41: $705-710$.

Jiang PP, Bedhomme S, Prasad NG, Chippindale A. 2011. Sperm competition and mate harm unresponsive to male-limited selection in Drosophila: An evolving genetic architecture under domestication. Evol 65: 2448-2460.

Johnstone RA, Keller L. 2000. How males can gain by harming their mates: Sexual conflict, seminal toxins, and the cost of mating. Am Nat 156: 368-377.

Kapelnikov A, Zelinger E, Gottlieb Y, Rhrissorrakrai K, Gunsalus KC, Heifetz Y. 2008. Mating induces an immune response and developmental switch in the Drosophila oviduct. Proc Natl Acad Sci 105: 13912-13917.

Karn RC, Clark NL, Nguyen ED, Swanson WJ. 2008. Adaptive evolution in rodent seminal vesicle secretion proteins. Mol Biol Evol 25: 2301-2310.

Kershaw-Young CM, Druart X, Vaughan J, Maxwell WM. 2012. $\beta$-Nerve growth factor is a major component of alpaca seminal plasma and induces ovulation in female alpacas. Reprod Fertil Dev 24: 1093-1097.

Kilgallon SJ, Simmons LW. 2005. Image content influences men's semen quality. Biol Lett 1: 253-255.

Kim YJ, Bartalska K, Audsley N, Yamanaka N, Yapici N, Lee JY, Kim YC, Markovic M, Isaac E, Tanaka Y, et al. 2010. MIPs are ancestral ligands for the sex peptide receptor. Proc Natl Acad Sci 107: 6520-6525.

Kingan SB, Tatar M, Rand DM. 2003. Reduced polymorphism in the chimpanzee semen coagulating protein, semenogelin I. J Mol Evol 57: 159-169.

Kubli E. 2003. Sex-peptides: Seminal peptides of the Drosophila male. Cell Mol Life Sci 60: 1689-1704.
LaFlamme BA, Wolfner MF. 2013. Identification and function of proteolysis regulators in seminal fluid. Mol Reprod Dev 80: 80-101.

LaFlamme BA, Ravi Ram K, Wolfner MF. 2012. The Drosophila melanogaster seminal fluid protease "seminase" regulates proteolytic and post-mating reproductive processes. PLoS Genet 8: e1002435.

LaFlamme BA, Avila FW, Ravi Ram K, Wolfner MF. 2014. A Drosophila protease cascade member, seminal metalloprotease-1, is activated stepwise by male factors and require female factors for full activity. Genetics 196: $1117-1129$.

Lawniczak MK, Begun DJ. 2004. A genome-wide analysis of courting and mating responses in Drosophila melanogaster females. Genome 47: 900-910.

Leiblich A, Marsden L, Gandy C, Corrigan L, Jenkins R, Hamdy F, Wilson C. 2012. Bone morphogenetic proteinand mating-dependent secretory cell growth and migration in the Drosophila accessory gland. Proc Natl Acad Sci 109: 19292-19297.

Lessells CM. 2005. Why are males bad for females? Models for the evolution of damaging male mating behavior. $A m$ Nat 165: S46-S63.

Li H, Huang S, Guo C, Guan H, Xiong C. 2012. Cell-free seminal mRNA and microRNA exist in different forms. PLoS ONE 7: e34566.

Linklater JR, Wertheim B, Wigby S, Chapman T. 2007. Ejaculate depletion patterns evolve in response to experimental manipulation of sex ratio in Drosophila melanogaster. Evol 61: 2027-2034.

Loher W, Ganjian I, Kubo I, Stanley-Samuelson D, Tobe SS. 1981. Prostaglandins: Their role in egg-laying of the cricket Teleogryllus commodus. Proc Natl Acad Sci 78: 7835-7838.

Lung O, Wolfner MF. 1999. Drosophila seminal fluid proteins enter the circulatory system of the mated female fly by crossing the posterior vaginal wall. Insect Biochem Molec 12: 1043-1052.

Lung O, Tram U, Finnerty CM, Eipper-Mains MA, Kalb JM, Wolfner MF. 2002. The Drosophila melanogaster seminal fluid protein Acp62F is a protease inhibitor that is toxic upon ectopic expression. Genetics 160: 211-224.

Lüpold S, Pitnick S, Berben KS, Blengini CS, Belote JM, Manier MK. 2013. Female mediation of competitive fertilization success in Drosophila melanogaster. Proc Natl Acad Sci 110: 10693-10698.

Mack PD, Kapelnikov A, Heifetz Y, Bender M. 2006. Mating-responsive genes in reproductive tissues of female Drosophila melanogaster. Proc Natl Acad Sci 103: 10358-10363.

Mancini E, Tammaro F, Baldini F, Via A, Raimondo D, George P, Audisio P, Sharakhov IV, Tramontano A, Catteruccia F, et al. 2011. Molecular evolution of a gene cluster of serine proteases expressed in the Anopheles gambiae female reproductive tract. BMC Evol Biol 11.

* Mank JE, Hosken DJ, Wedell N. 2014. Conflict on the sex chromosomes: Cause, effect, and complexity. Cold Spring Harb Perspect Biol doi: 10.1101/cshperspect.a017715.

Martan J, Shepherd BA. 1976. The role of the copulatory plug in reproduction of the guinea pig. J Exp Zool 196: $79-84$. 
L.K. Sirot et al.

McGraw LA, Gibson G, Clark AG, Wolfner MF. 2004. Genes regulated by mating, sperm, or seminal proteins in mated female Drosophila melanogaster. Curr Biol 14: 1509_ 1514.

Moshitzky P, Fleischmann I, Chaimov N, Saudan P, Klauser S, Kubli E, Applebaum SW. 1996. Sex-peptide activates juvenile hormone biosynthesis in the Drosophila melanogaster corpus allatum. Arch Insect Biochem Physiol 32: 363-374.

Mueller JL, Ripoll DR, Aquadro CF, Wolfner MF. 2004. Comparative structural modeling and inference of conserved protein classes in Drosophila seminal fluid. Proc Natl Acad Sci 101: 13542-13547.

Mueller JL, Ravi Ram K, McGraw LA, Bloch Qazi MC, Siggia ED, Clark AG, Aquadro CF, Wolfner MF. 2005. Crossspecies comparison of Drosophila male accessory gland protein genes. Genetics 171: 131-143.

Mueller JL, Page JL, Wolfner MF. 2007. An ectopic expression screen reveals the protective and toxic effects of Drosophila seminal fluid proteins. Genetics 175: 777-783.

Naccarati C, Audsley N, Keen JN, Kim JH, Howell GJ, Kim YJ, Isaac RE. 2012. The host-seeking inhibitory peptide, Aea-HP-1, is made in the male accessory gland and transferred to the female during copulation. Peptides 34: $150-157$.

Nandy B, Gupta V, Sen S, Udaykumar N, Samant MA, Ali SZ, Prasad NG. 2013. Evolution of mate-harm, longevity and behavior in male fruit flies subjected to different levels of interlocus conflict. BMC Evol Biol 13: 212.

Neubaum DM, Wolfner MF. 1999. Wise, winsome, or weird? Mechanisms of sperm storage in female animals. Curr Top Dev Biol 41: 67-97.

Pampalakis G, Sotiropoulou G. 2007. Tissue kallikrein proteolytic cascade pathways in normal physiology and cancer. Biochim Biophys Acta 1776: 22-31.

Panhuis TM, Clark NL, Swanson WJ. 2006. Rapid evolution of reproductive proteins in abalone and Drosophila. Philos Trans R Soc B 361: 261-268.

Park M, Wolfner MF. 1995. Male and female cooperate in the prohormone-like processing of a Drosophila melanogaster seminal fluid protein. Dev Biol 171: 694-702.

Parker GA. 1979. Sexual selection and sexual conflict. In Sexual selection and reproductive competition in insects (ed. Blum MS, Blum NA), pp. 123-166. Academic, New York.

Parker GA. 2006. Sexual conflict over mating and fertilization: An overview. Philos Trans R Soc B 361: 235-259.

Partridge L, Gems D. 2002. Mechanisms of ageing: Public or private? Nat Rev Genet 3: 165-175.

Peng J, Chen S, Busser S, Liu H, Honegger T, Kubli E. 2005. Gradual release of sperm bound sex-peptide controls female postmating behavior in Drosophila. Curr Biol 15: 207-213.

Perry JC, Sirot L, Wigby S. 2013. The seminal symphony: How to compose an ejaculate. Trends Ecol Evol 28: 414422.

Pilch B, Mann M. 2006. Large-scale and high-confidence proteomic analysis of human seminal plasma. Genome Biol 7: R40.
Pitnick S, Brown WD, Miller GT. 2001. Evolution of female remating behaviour following experimental removal of sexual selection. Proc Biol Sci 268: 557-563.

Poels J, Van Loy T, Vandersmissen HP, Van Hiel B, Van Soest S, Nachman RJ, Vanden Broeck J. 2010. Myoinhibiting peptides are the ancestral ligands of the promiscuous Drosophila sex peptide receptor. Cell Mol Life Sci 67: 3511-3522.

Poiani A. 2006. Complexity of seminal fluid: A review. Behav Ecol Sociobiol 60: 289-310.

Prokupek AM, Kachman SD, Ladunga I, Harshman LG. 2009. Transcriptional profiling of the sperm storage organs of Drosophila melanogaster. Insect Mol Biol 18: 465475.

Ramm SA, Oliver PL, Ponting CP, Stockley P, Emes RD. 2008. Sexual selection and the adaptive evolution of mammalian ejaculate proteins. Mol Biol Evol 25: 207219.

Ramm SA, McDonald L, Hurst JL, Beynon RJ, Stockley P. 2009. Comparative proteomics reveals evidence for evolutionary diversification of rodent seminal fluid and its functional significance in sperm competition. Mol Biol Evol 26: 189-198.

Ratto MH, Leduc YA, Valderrama XP, van Straaten KE, Delbaere LT, Pierson RA, Adams GP. 2012. The nerve of ovulation-inducing factor in semen. Proc Natl Acad Sci 109: 15042-15047.

Ravi Ram K, Wolfner MF. 2007. Seminal influences: Drosophila Acps and the molecular interplay between males and females during reproduction. Integr Comp Biol 47: 427-445.

Ravi Ram K, Wolfner MF. 2009. A network of interactions among seminal proteins underlies the long-term postmating response in Drosophila. Proc Natl Acad Sci 106: 15384-15389.

Ravi Ram K, Sirot LK, Wolfner MF. 2006. Predicted seminal astacin-like protease is required for processing of reproductive proteins in Drosophila melanogaster. Proc Natl Acad Sci 103: 18674-18679.

Ribeiro C, Dickson BJ. 2010. Sex peptide receptor and neuronal TOR/S6K signaling modulate nutrient balancing in Drosophila. Curr Biol 20: 1000-1005.

Rice WR. 1984. Sex chromosomes and the evolution of sexual dimorphism. Evolution 38: 735-742.

Rice WR. 1996. Sexually antagonistic male adaptation triggered by experimental arrest of female evolution. Nature 381: 232-234.

Rice WR. 1998. Male fitness increases when females are eliminated from gene pool: Implications for the Y chromosome. Proc Natl Acad Sci 95: 6217-6221.

Robertson SA. 2007. Seminal fluid signaling in the female reproductive tract: Lessons from rodents and pigs. JAnim Sci 85: E36-E44.

Robertson SA, Guerin LR, Moldenhauer LM, Hayball JD. 2009. Activating $T$ regulatory cells for tolerance in early pregnancy-The contribution of seminal fluid. J Reprod Immunol 83: 109-116.

Rodriguez-Martinez H, Kvist U, Ernerudh J, Sanz L, Calvete JJ. 2011. Seminal plasma proteins: What role do they play? Am J Reprod Immunol 66: 11-22. 
Rogers DW, Baldini F, Battaglia F, Panico M, Dell A, Morris HR, Catteruccia F. 2009. Transglutaminase-mediated semen coagulation controls sperm storage in the malaria mosquito. PLoS Biol 7: e1000272.

Rowe L, Cameron E, Day T. 2003. Detecting sexually antagonistic coevolution with population crosses. Proc Biol Sci 270: 2009-2016.

Rowe L, Cameron E, Day T. 2005. Escalation, retreat, and female indifference as alternative outcomes of sexually antagonistic coevolution. Am Nat 165: S5-S18.

Rubinstein CD, Wolfner MF. 2013. Drosophila seminal protein ovulin mediates ovulation through female octopamine neuronal signaling. Proc Natl Acad Sci 110: $17420-17425$.

Sasanami T, Matsuzaki M, Mizushima S, Hiyama G. 2013. Sperm storage in the female reproductive tract in birds. $J$ Reprod Dev 59: 334-338.

Schumacher J, Rosenkranz D, Herlyn H. 2014. Mating systems and protein-protein interactions determine evolutionary rates of primate sperm proteins. Proc Biol Sci 281: 20132607.

Sharkey DJ, Tremellen KP, Jasper MJ, Gemzell-Danielsson K, Robertson SA. 2012. Seminal fluid induces leukocyte recruitment and cytokine and chemokine mRNA expression in the human cervix after coitus. J Immunol 188: 2445-2454.

Short SM, Lazzaro BP. 2010. Female and male genetic contributions to post-mating immune defence in female Drosophila melanogaster. Proc Biol Sci 277: 3649-3657.

Short SM, Wolfner MF, Lazzaro BP. 2012. Female Drosophila melanogaster suffer reduced defense against infection due to seminal fluid components. J Insect Physiol 58: 11921201.

Siegel RW, Hall JC. 1979. Conditioned responses in courtship behavior of normal and mutant Drosophila. Proc Natl Acad Sci 76: 3430-3434.

Simmons LW, Tan YF, Millar AH. 2013. Sperm and seminal fluid proteomes of the field cricket Teleogryllus oceanicus: Identification of novel proteins transferred to females at mating. Insect Mol Biol 22: 115-130.

Sirot LK, Poulson RL, McKenna MC, Girnary H, Wolfner MF, Harrington LC. 2008. Identity and transfer of male reproductive gland proteins of the dengue vector mosquito, Aedes aegypti: Potential tools for control of female feeding and reproduction. Insect Biochem Mol Biol 38: $176-189$.

Sirot LK, LaFlamme BA, Sitnik JL, Rubinstein CD, Avila FW, Chow CY, Wolfner MF. 2009. Molecular social interactions: Drosophila melanogaster seminal fluid proteins as a case study. Adv Genet 68: 23-56.

Sirot LK, Hardstone MC, Helinski ME, Ribeiro JM, Kimura M, Deewatthanawong P, Wolfner MF, Harrington LC. 2011. Towards a semen proteome of the dengue vector mosquito: Protein identification and potential functions. PLoS Negl Trop Dis 5: e989.

Sirot LK, Findlay G, Sitnik J, Frasheri D, Avila F, Wolfner MF. 2014. Molecular characterization and evolution of a gene family encoding both female- and male-specific reproductive proteins in Drosophila. Mol Biol Evol 31: 15541567.
Smith DT, Hosken DJ, Ffrench-Constant RH, Wedell N. 2009. Variation in sex peptide expression in D. melanogaster. Genet Res (Camb) 91: 237-242.

South A, Sirot LK, Lewis SM. 2011. Identification of predicted seminal fluid proteins in Tribolium castaneum. Insect Mol Biol 20: 447-456.

Suarez SS. 2008. Regulation of sperm storage and movement in the mammalian oviduct. Int J Dev Biol 52: 455-462.

Swanson WJ, Vacquier VD. 2002. The rapid evolution of reproductive proteins. Nat Rev Genet 3: 137-144.

Swanson WJ, Clark AG, Waldrip-Dail HM, Wolfner MF Aquadro CF. 2001. Evolutionary EST analysis identifies rapidly evolving male reproductive proteins in Drosophila. Proc Natl Acad Sci 98: 7375-7379.

Swanson WJ, Wong A, Wolfner MF, Aquadro CF. 2004. Evolutionary expressed sequence tag analysis of Drosophila female reproductive tracts identifies genes subjected to positive selection. Genetics 168: 1457-1465.

Tregenza T, Wedell N, Chapman T. 2006. Introduction. Sexual conflict: A new paradigm? Philos Trans R Soc B 361: 229-234.

Turner LM, Chuong EB, Hoekstra HE. 2008. Comparative analysis of testis protein evolution in rodents. Genetics 179: $2075-2089$.

Vandersmissen HP, Nachman RJ, Vanden Broeck J. 2013. Sex peptides and MIPs can activate the same G protein-coupled receptor. Gen Comp Endocrinol 188: 137-143.

Wagstaff BJ, Begun DJ. 2005. Comparative genomics of accessory gland protein genes in Drosophila melanogaster and D. pseudoobscura. Mol Biol Evol 22: 818-832.

Wagstaff BJ, Begun DJ. 2007. Adaptive evolution of recently duplicated accessory gland protein genes in desert Drosophila. Genetics 177: 1023-1030.

Walters JR, Harrison RG. 2008. EST analysis of male accessory glands from Heliconius butterflies with divergent mating systems. BMC Genomics 9: 592.

Walters JR, Harrison RG. 2010. Combined EST and proteomic analysis identifies rapidly evolving seminal fluid proteins in Heliconius butterflies. Mol Biol Evol 27: 2000-2013.

Wedell N, Gage MJG, Parker GA. 2002. Sperm competition, male prudence and sperm-limited females. Trends Ecol Evol 17: 313-320.

Weiss BL, Kaufman WR. 2004. Two feeding-induced proteins from the male gonad trigger engorgement of the female tick Amblyomma hebraeum. Proc Natl Acad Sci 101: $5874-5879$.

West Eberhard MJ. 1979. Sexual selection, social competition, and evolution. Proc Am Phil Soc 123: 222-234.

Wigby S, Chapman T. 2004. Female resistance to male harm evolves in response to manipulation of sexual conflict. Evol 58: 1028-1037.

Wigby S, Chapman T. 2005. Sex peptide causes mating costs in female Drosophila melanogaster. Curr Biol 15:316-321.

Wigby S, Sirot LK, Linklater JR, Buehner N, Calboli FC, Bretman A, Wolfner MF, Chapman T. 2009. Seminal fluid protein allocation and male reproductive success. Curr Biol 19: 751-757.

Wlaskiuk G, Nachman MW. 2010. Promiscuity and the rate of molecular evolution at primate immunity genes. Evolution 64: 2204-2220. 
L.K. Sirot et al.

Wong A. 2010. Testing the effects of mating system variation on rates of molecular evolution in primates. Evolution 64: $2779-2785$.

Wong A. 2011. The molecular evolution of animal reproductive tract proteins: What have we learned from mating-system comparisons? Int J Evol Biol 2011: 1-9.

Wong A, Rundle HD. 2013. Selection on the Drosophila seminal fluid protein Acp62F. Ecol Evol 3: 1942-1950.

Wong A, Albright SN, Giebel JD, Ram KR, Ji S, Fiumera AC, Wolfner MF. 2008. A role for Acp29AB, a predicted seminal fluid lectin, in female sperm storage in Drosophila melanogaster. Genetics 180: 921-931.

Xue L, Noll M. 2000. Drosophila female sexual behavior induced by sterile males showing copulation complementation. Proc Natl Acad Sci 97: 3272-3275.
Yang CH, Rumpf S, Xiang Y, Gordon MD, Song W, Jan LY, Jan YN. 2009. Control of the postmating behavioral switch in Drosophila females by internal sensory neurons. Neuron 61: 519-526.

Yapici N, Kim YJ, Ribeiro C, Dickson BJ. 2008. A receptor that mediates the post-mating switch in Drosophila reproductive behaviour. Nature 451: 33-37.

Zawistowski S, Richmond RC. 1986. Inhibition of courtship and mating of Drosophila melanogaster by the male-produced lipid, cis-vaccenyl acetate. JInsect Physiol 32: 189-192.

Zhong W, McClure CD, Evans CR, Mlynski DT, Immonen E, Ritchie MG, Priest NK. 2013. Immune anticipation of mating in Drosophila: Turandot $M$ promotes immunity against sexually transmitted fungal infections. Proc Bio Sci 280: 20132018. 


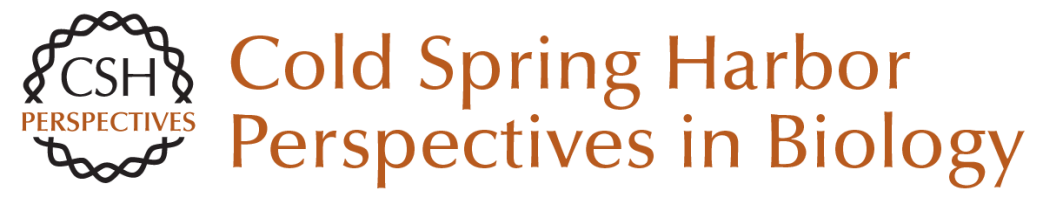

\title{
Sexual Conflict and Seminal Fluid Proteins: A Dynamic Landscape of Sexual Interactions
}

\author{
Laura K. Sirot, Alex Wong, Tracey Chapman and Mariana F. Wolfner
}

Cold Spring Harb Perspect Biol 2015; doi: 10.1101/cshperspect.a017533 originally published online December 11, 2014

\section{Subject Collection The Genetics and Biology of Sexual Conflict}

Mechanisms and Evidence of Genital

Coevolution: The Roles of Natural Selection, Mate

Choice, and Sexual Conflict

Patricia L.R. Brennan and Richard O. Prum

The Evolution of Sexually Antagonistic

Phenotypes

Jennifer C. Perry and Locke Rowe

Reproductive Parasitism: Maternally Inherited

Symbionts in a Biparental World

Gregory D.D. Hurst and Crystal L. Frost

Sex-Biased Gene Expression and Sexual Conflict throughout Development

Fiona C. Ingleby, Ilona Flis and Edward H. Morrow

Human Homosexuality: A Paradigmatic Arena for

Sexually Antagonistic Selection?

Andrea Camperio Ciani, Umberto Battaglia and Giovanni Zanzotto

Sexual Conflict Arising from Extrapair Matings in Birds

Alexis S. Chaine, Robert Montgomerie and Bruce E. Lyon

Sexual Conflict and Seminal Fluid Proteins: A Dynamic Landscape of Sexual Interactions

Laura K. Sirot, Alex Wong, Tracey Chapman, et al.
Infanticide as Sexual Conflict: Coevolution of

Male Strategies and Female Counterstrategies Ryne A. Palombit

Copulatory Wounding and Traumatic

Insemination

Klaus Reinhardt, Nils Anthes and Rolanda Lange

Sexual Conflict in Hermaphrodites

Lukas Schärer, Tim Janicke and Steven A. Ramm

Sexual Conflict and Sperm Competition

Dominic A. Edward, Paula Stockley and David J. Hosken

Sexually Antagonistic Zygotic Drive: A New Form of Genetic Conflict between the Sex

Chromosomes Urban Friberg and William R. Rice

Sex Chromosome Drive

Quentin Helleu, Pierre R. Gérard and Catherine Montchamp-Moreau

Is Sexual Conflict an "Engine of Speciation"? Sergey Gavrilets

For additional articles in this collection, see http://cshperspectives.cshlp.org/cgi/collection/

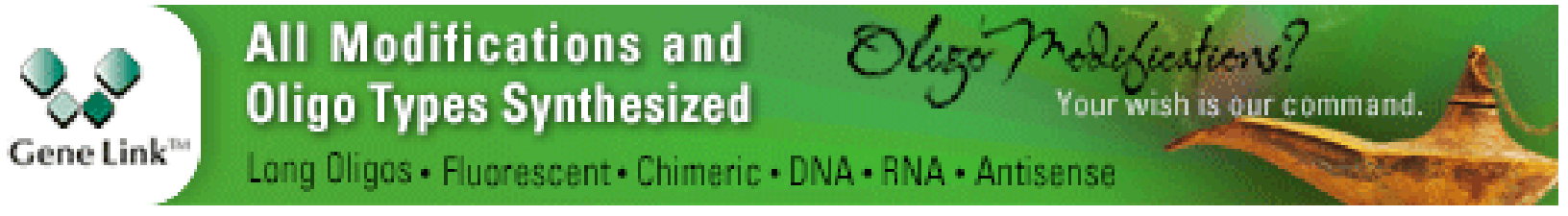

Copyright @ 2015 Cold Spring Harbor Laboratory Press; all rights reserved 
Conflict on the Sex Chromosomes: Cause, Effect, and Complexity

Judith E. Mank, David J. Hosken and Nina Wedell
Sexual Cannibalism as a Manifestation of Sexual

Conflict

Jutta M. Schneider

For additional articles in this collection, see http://cshperspectives.cshlp.org/cgi/collection/

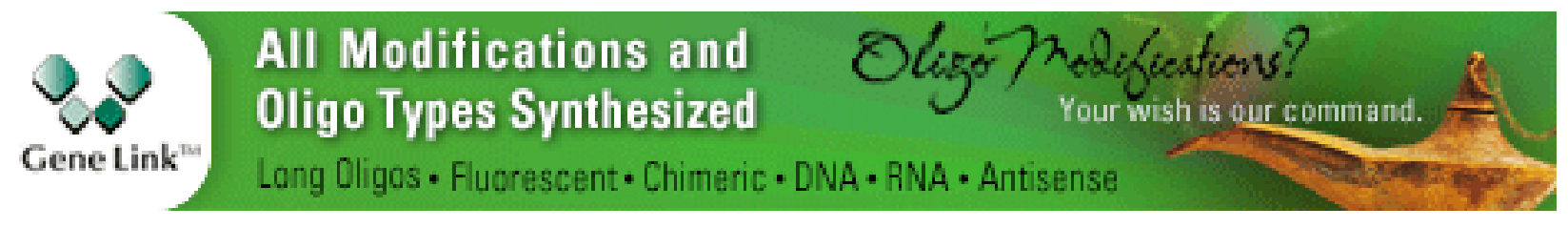

Copyright @ 2015 Cold Spring Harbor Laboratory Press; all rights reserved 